\title{
Los espacios ajardinados en la musivaria romana
}

\author{
María Pilar San Nicolás Pedraz *
}

\begin{abstract}
RESUMEN
ABSTRACT

Análisis de los mosaicos con Mosaics which represent gardens and representaciones de jardines $y$ las estructuras arquitectónicas relacionadas

con ellos. Estudio de las perspectivas utilizadas, relación de las manifestaciones pictóricas y su perduración en época posterior. the architectural structures related with them are analysed here. Furthermore, the perspectives, the relation to painted pictures and their continuity in later epoch are presented.
\end{abstract}

Como origen de los jardines romanos puede considerarse el hortus, pequeño y modesto recinto al cuidado de la madre de familia, en el que se cultivaban hortalizas para el propio consumo, flores para el culto y plantas medicinales (Tito Livio, 1 56; Plinio, Hist. Nat. XIX 50-53; Catón De re rust. 8). Sin embargo, el jardin propiamente dicho o espacio ajardinado concedido para el descanso y placer, ya sea público o privado, no comienza hasta los siglos II y I a.C., como consecuencia de la suntuocidad y costumbres que trajeron las victorias romanas de Oriente, siendo durante los últimos tiempos de la República y principios del Imperio uno de los grandes lujos de la aristocracia. Plinio decía que "Hoy en Roma se posee, con el nombre de jardines, lugares de placer, campos, villas; se vive la campiña en la ciudad" (Hist. Nat. 50-51). A lo largo del Imperio los jardines de la urbs fueron limitándose, aunque no faltaron en las domus señoriales ni en las grandes propiedades rurales del Bajo Imperio ${ }^{1}$.

UNED. Madrid.

Para los jardines en general cf. P. GrimaL, Les jardins romains. París, 1969 (Troisième edition 1984); E.B. MACDOUGAL-W.F. JASHEMSKI (edd.), Ancient Roman Gardens, Washington, D.C. 1981 ; J. DixON Hunt, Garden and Grove, Princeton. New Jersey, 1986. Y en particular cf. W.F. JASHEMSKI, The 
La musivaria romana con representaciones de espacios ajardinados responde, al igual que la pintura u otro arte, al gusto de los romanos por la naturaleza como prolongación del verdor y bienestar de sus jardines públicos y privados. Aparecen tanto en las domus como en las villae, pavimentando diferentes espacios que corresponden la mayoría al oecus, triclinium, vestibulum y los cubicula, además de las paredes de los ninfeos y columnas de la pérgola; con una amplia cronología que oscila entre el siglo I hasta la Antigüedad tardía.

En algunas de estas figuraciones es dificil distinguir la zona ajardinada que se ha querido representar; en otras la panorámica y las estructuras arquitectónicas son elementos indicativos que resaltan si pertenecen a espacios urbanos o rurales, así como a exteriores o interiores. En cuanto al esquema compositivo el jardín se figura de dos formas diferentes, como tema principal o como elemento secundario del cuadro, pero a la vez es parte esencial del mismo. Para ello se utiliza la perspectiva lineal, tanto la cónica como la abatida, vista en alzado o en planta.

La flora que se identifica, en gran parte importada de Asia, es muy variada, alternándose las flores con los arbustos decorativos y los árboles frutales. Entre las plantas más figuradas se encuentran el laurel (laurus), mencionado frecuentementes por los autores antiguos (Plinio, Hist. Nat. XV 130-137; Virg. Ecl. II 54; Ov. Ars. am. III 690), y el acanto (acanthus), cuyas bellas hojas producen un acertado efecto en los trazados del jardín (Plinio Epist. V 6, 16; Hist. Nat. XXII 76); siendo la rosa la flor principal ${ }^{2}$. Dentro de la fauna aparecen peces y aves, en estas últimas destaca la paloma ${ }^{3}$. En la composición del espacio no faltan la representaciones de balaustradas, esculturas, fuentes, veneras, cráteras y cestos con frutos 0 flores que complementan la decoración y realzan la belleza del jardín romano (Plinio Epist. V 6, 36 y 40).

Gardens of Pompeii, Herculaneum and the Villa Destroyed by Vesuvius, New Rochelle, New Rochelle. New Yord, 1979; J. DE ALARCAO y R. ETIENNE, "Les jardins à Conimbriga (Portugal)", en E. MCDOUgal-W.F. JASHemski, op. cit., 69-77; W. JashemSKI-E. Salza Prina RicotTI, «Preliminary excavations in the Gardens of Hadrian's Villa: The Canopus Area and the Piazza d'Oro", Ameritan Journal of Archacology 96, 1992, 593-595; W.F. JASHEMSKi, "Roman Gardens in Tunisia and The Vesuvian area», Actas del XIV Congreso Internacional de Arq. Clásica (Tarragona 1993), 1994, vol. 1, $239-244$.

2 Para las diferentes especies de plantas cf. Theophr. Hist. Plant. I y III; Plinio Hist. Nat. La rosa es de origen persa y se cultivó en Grecia ya en tiempos de Homero (Hymn. in Cer. 427; Philos. Espist. 71; Anacr. fr. 83; Pind. 75, 18; Herod. VIII 138), Plinio no menciona ninguna otra flor más que las rosas al describir sus dos villas (Epist. $\vee 6,34$ ), y particularmente la rosa blanca (Hist. Nat. XXI 16). Para el tema de la rosa cf., J.-N. RoBert, "Un symbole dans l'Antiquité. Au nom. de la rose", Historama, 95, 1992, 74-79.

3 Según Varron, los grandes propietarios poseian en sus villas un palomar, costumbre heredada de los Lágidas (R.R., I). 
De acuerdo con estas premisas, las representaciones más antiguas de jardín en la musivaria romana se encuentran en cuatro ejemplares de Campania, del siglos $1-11$, de los cuales dos decoraban sendos ninfeas y los otros las columnas de una pérgola y el suelo de una domus respectivamente. EI primero, de pasta vítrea y conchas, procede de la Casa "del bracciale d'oro" (VI, 17, 42) de Pompeya, situado en el ábside de la pared del fondo del triclinium de verano ${ }^{4}$. El nicho presenta en el centro una apertura rectangular que deja visible una escalera de doce escalones que estaba en comunicación, en la parte alta, con una escalera para el agua que caía desde arriba al estanque situado en la parte inferior. La bóveda del ábside está

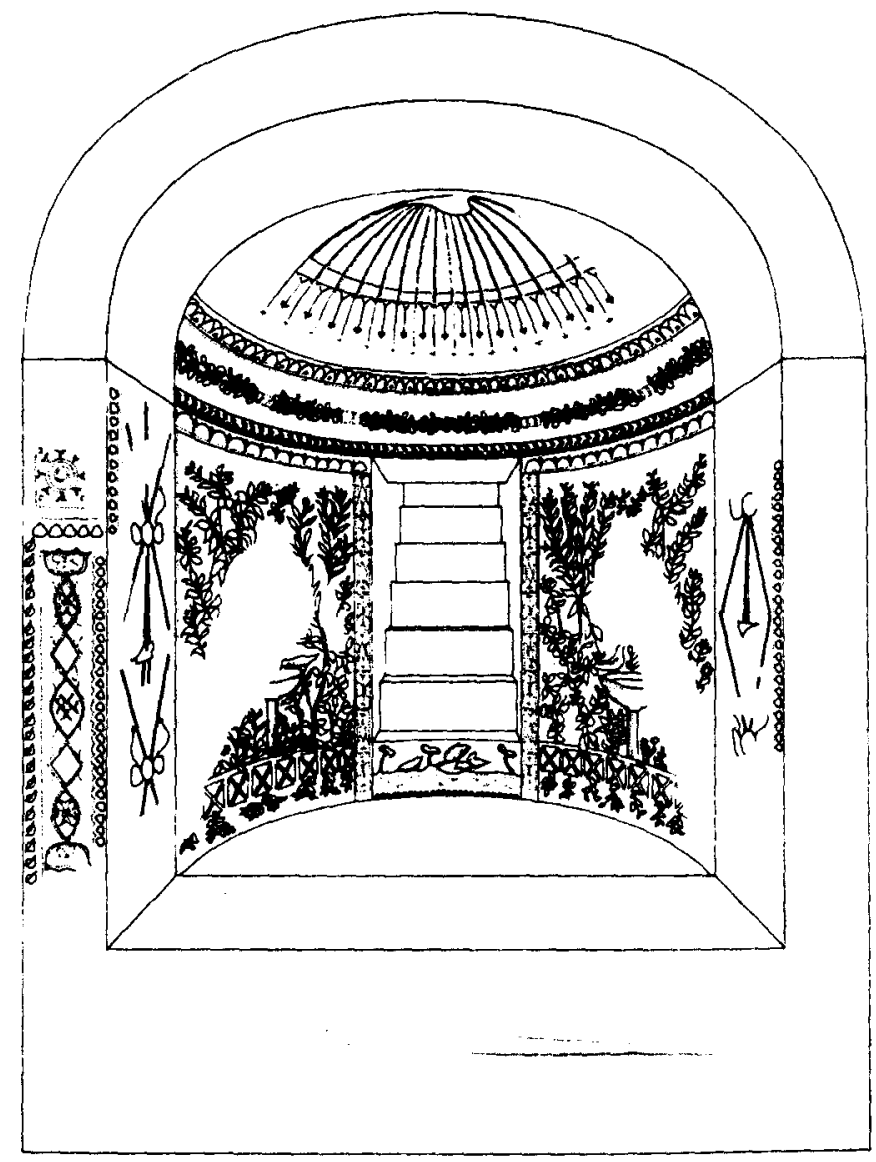

Figura 1. Mosaico de Pompeya. Casa "del bracciale d'oro".

4 VV.AA. Pompeji Wiederentdeclat. Roma, 1993, 270-280, nº 194. 
decorada con una venera tridimensional, motivo propiamente pompeyano ${ }^{5}$, delimitada, en la parte inferior, por una guirnalda de hojas de laurel, margaritas y frutos (membrillos y peras); mientras que en el arco aparecen motivos fitomorfos y geométricos (figura 1). La pared del ábside presenta, a ambos lados de la apertura para la escalera, dos paneles simétricos con idéntico tema de espacio ajardinado. Este jardín de notable efecto ilusionista, similar a los representados en las pinturas ${ }^{6}$, está cercado por una balaustrada por donde escapan algunas ramas; sobre el fondo destaca plantas de varias especies, arbustos, flores de diversos colores y, en el centro, una pequeña fuente de pie alto, llena de agua, con surtidor central, sobre el

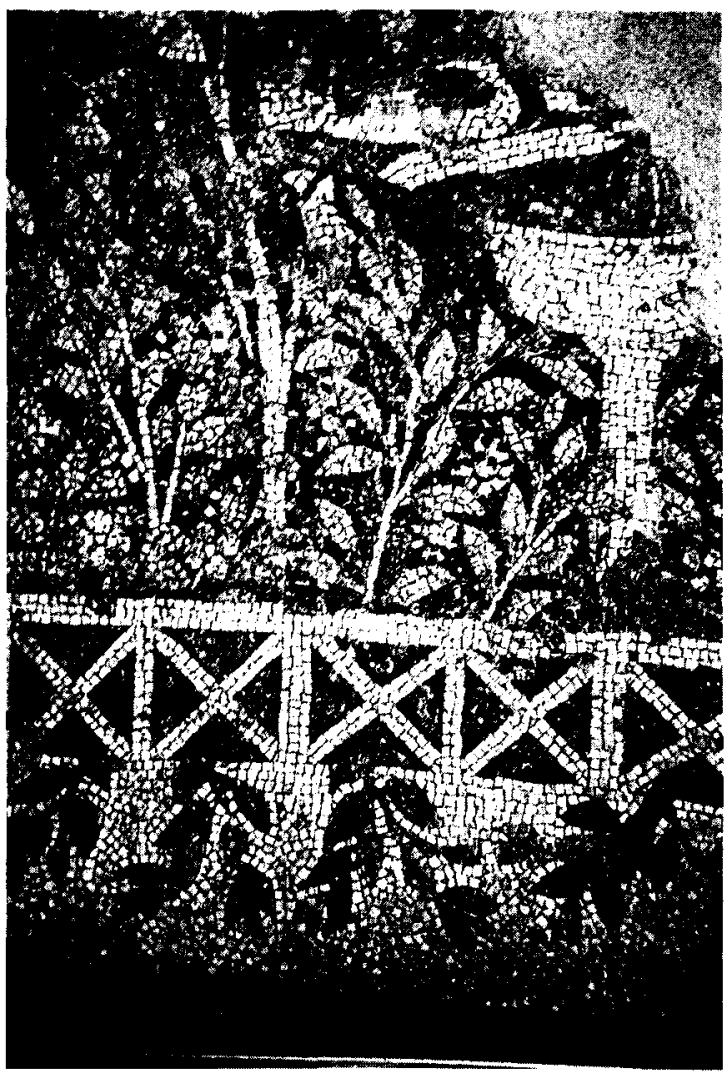

Figura 2. Detalle del Mosaico de Pompeya. Casa "del bracciale d'oro".

A. Ovadiah, Geometric and Floral Patterns in Ancient Mosaic. Roma, 1980, 153. W.F. JASHEMSKI (1979), op. cit. (n. 1), 55-87. 
borde de la cual se posan palomas (figura 2). En la parte inferior de la apertura central hay un pequeño panel en el que se ha figurado un lago con ánades y flores de loto (Nelumbo nucifera), respondiendo al gusto romano por las plantas acuáticas (Plinio Hist. Nat. XII 56 y 76).

El segundo mosaico parietal procede de Baiae y se conserva en el Museo de Cambridge ${ }^{7}$. Se compone de dos zonas: una bóveda adornada con una venera de diez gallones; y un cuerpo en el que figura el jardín con varias plantas y palomas volando, rodeado de balaustrada en donde está posado un pavo real, animal exaltado por su arrogancia y belleza en los versos de Ovidio (Met. 1 722) y tan frecuente en las pinturas de Pompeya, como la de la Casa de Romulo y Remo (VII 7, 10), y en los parques de Roma ${ }^{8}$ (figura 3).

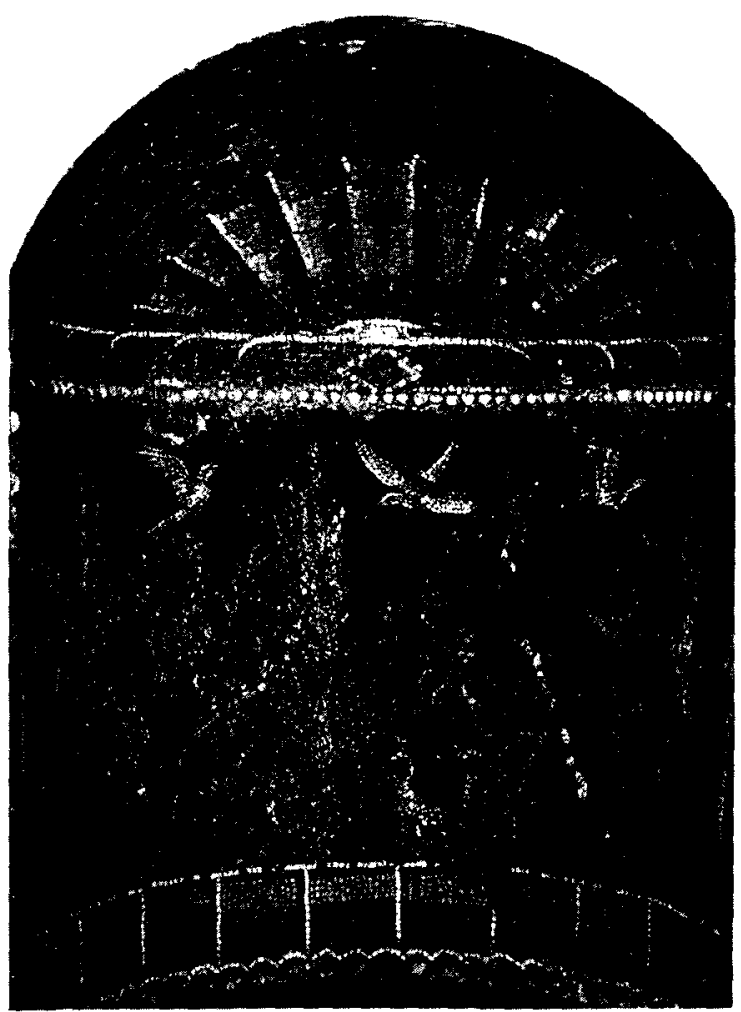

Figura 3. Mosaico de Baiae.

Ibidem. 67, fig. 108.

\& P. Grimal, op. cit. (n.1), 290 
El tercero aparece decorando las columnas que rodeaban una fuente de surtidor en la villa de las Columnas en Mosaico de Pompeya, actualmente en el Museo Nazionale de Nápoles ${ }^{9}$. Muestra dos frisos separados por una guirnalda de laurel: el registro superior está decorado con una serie de flores (margaritas, rosas y campánulas); el registro inferior ofrece una composición romboidal de escamas oblongas adyacentes, en oposición de cuatro colores ${ }^{10}$ (figura 4).

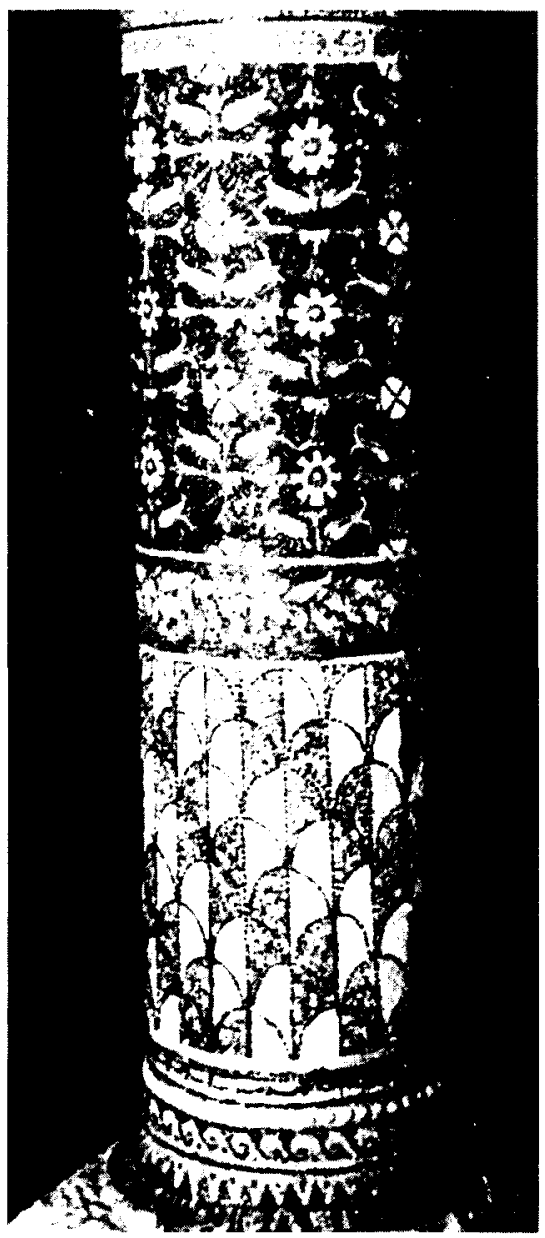

Figura 4. Mosaico de Pompeya. Villa de las Columnas en Mosaico.

A. MaIuHi, Pompeii. Novara, 1956, 152; W. F. JASHE MSkI (1979), op. cit. (n. 1), 151. fig. 239.

C. BAlmttlt et alii, Le décor geométrique de la mosaique romaine. Paris, 1985, 338, lám. 217e. 
El otro mosaico con escena de jardín, también de pasta vítrea, fue hallado en Roma, debajo de las termas de Constantino, en un ambiente perteneciente a una domus del siglo $10 \|^{11}$. El pavimento, de forma rectangular, presenta un fondo de hojas, rosas y membrillos, acompañados de dos ánforas y en el centro, entre ellas un cuadrado en donde destaca un pajarito (figura 5).

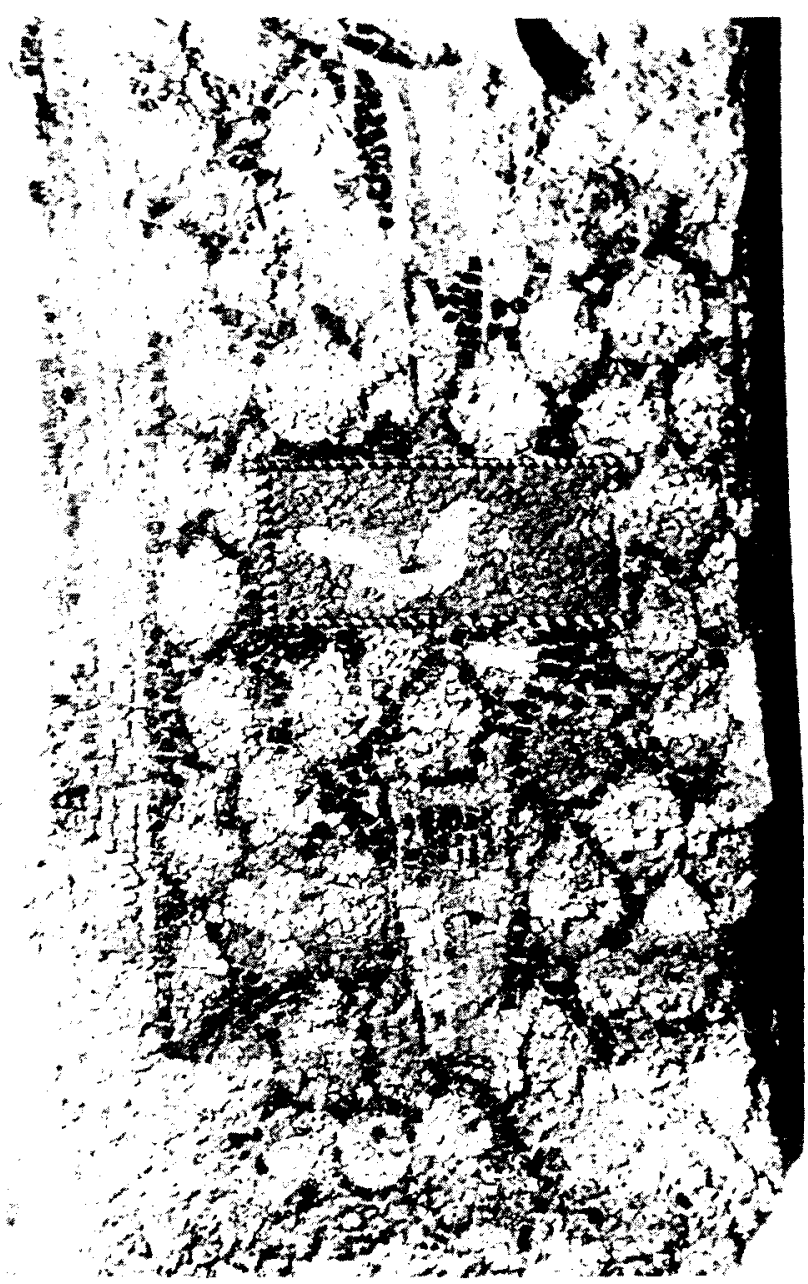

Figura 5. Mosaico de Roma. Termas de Constantino.

E. GA111 y F. SCorpr) A, "Relazioni su scavi, trovamenti, restauri». BullCom. XC, 1985, 77 fig. 5 . 
Como espacio ajardinado encerrado en el interior de una estructura arquitectónica, configurando el peristilo o patio interior porticado que está visto en perspectiva abatida, aparece en varios pavimentos del Bajo Imperio. Se utiliza dos modelos diferentes, uno con la figuración del peristilo como tema principal y otro integrado en una villa. Del primer tipo se documentan tres ejemplares. Uno de ellos es el mosaico hispano hallado en el vestibulum de la villa de Materno, en Carranque (Toledo), de mediados del sigio IV, en donde figura, rodeando el emblemata circular, una bordura arquitectónica representando esquemáticamente una vista del peristilo, con arquerías, columnas y un cancellum y tras él las plantas del jardín ${ }^{12}$ (figura 6).

Otro es el mosaico de la villa narboniense de Loupian (Hérault), que decoraba una sala de recepción trococónica, fechado en el último cuarto del siglo $\mathrm{N}$, muestra un gran pórtico rectangular de treinta pequeñas columnas, de las que se conservan restos de diez arcos y diez columnas

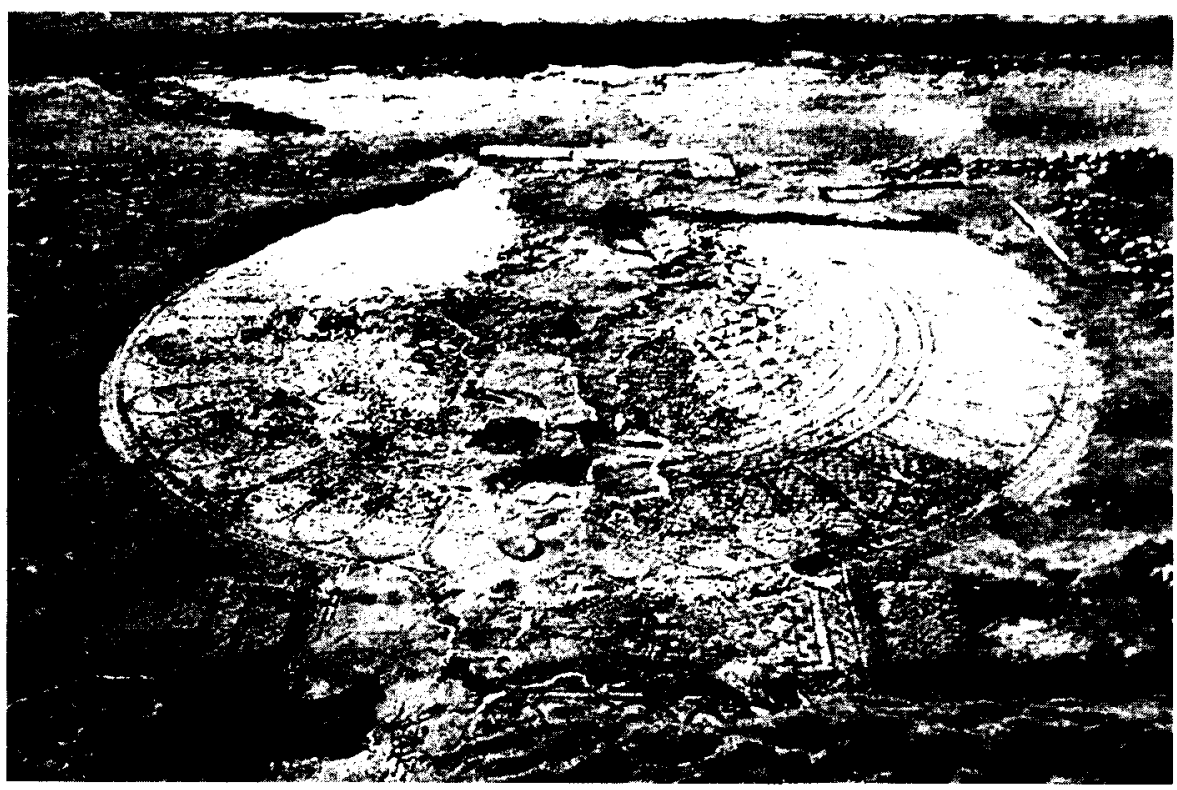

Figura 6. Mosaico de Carranque. Toledo.

D. Fl InANul /-Gal IANo, "La villa de Materno", Actas de la I Mesa Redonda Hispano-Francesa sobre Mosaicos (Madrid, 1985). Guadalajara, 1989, 258: Id., "The villa of Maternus at Carranque", Fifth International Colloquium on Ancient Mosaic (Bath, England, 1987), 1994, 203, fig. 4: D. Fi hnanth $z$-Gal. IANo et alii. "Mosaicos de la villa de Carranque: un programa iconogrático". VI Coloquio Internacional sobre Mosaico Antiguo (Palencia-Merida. 1990), 1994, 322. 
con capiteles decorados con motivos vegetales estilizados que componian tres de los cuatro lados de la superficie. Entre los vanos de las columnas centrales existen dos tipos de figuras, una es una crátera y la otra una venera y dos cornucopiae encerrando diversos objetos: vaso, pátera o simples nudos; mientras que los vanos de las columnas de los ángulos muestran un abundante follage con frutos cordiformes (posibles melocotones) (figura 7). La parte interior del pavimento está ocupada por una es-

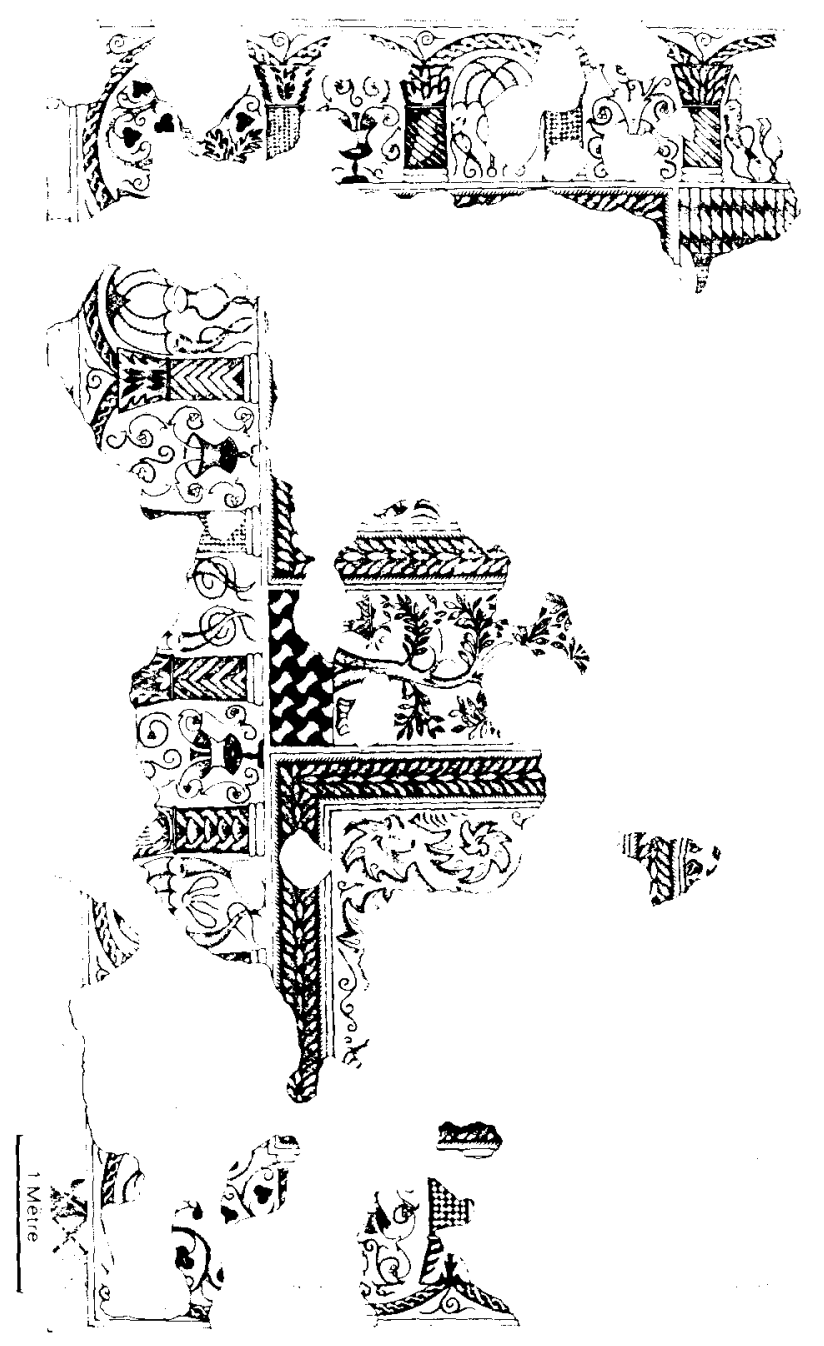

Figura 7. Mosaico de Loupian, Herault. 
tructura geométrica de guirnaldas de laurel a base de cuatro cuadrados en las esquinas con restos de follaje y de cuatro espacios oblongos, este último motivo aparece en mosaicos de las iglesias del Próximo Oriente y en el pavimento de la basílica paleocristiana de Delfos, fechados entre los siglos $|V-V|^{13}$. Uno de estos espacios oblongos que se encuentra casi intacto, presenta dos cestos de frutos encuadrando un árbol con frutos piriformes (peras). Árboles frutales se documentan, asimismo en otros pavimentos de Aquitania, datados también entre los siglos $|\mathrm{V}-\mathrm{V}|^{14}$.

En el pavimento africano de la Casa del Peristilo de Pupput (Hammamet), fechado en el primer cuarto del siglo $v$, aparece también el peristilo figurado de plano como los mosaicos anteriores pero con la diferencia de que está hacia adentro, con ocho columnas con basa y capitel, cuyos arcos reposan en los capiteles; las cuatro columnas del medio se presentan de frente y las otras cuatro de las esquinas en oblicuo ${ }^{15}$. El edificio está representado por una serie de líneas delimitando un rectángulo central, en donde aparece en el centro una fuente con surtidor. Entre las columnas están representados capullos de rosa evocando el jardín (figura 8).

El segundo tipo está representado en el mosaico hispano de las Cuatro Estaciones o de los Peces, procedente del triclinium de la villa de la Vega Baja de Toledo, que se data a principios del siglo IV ${ }^{16}$. En uno de los semicírculos que rodean al emblemata figura, dentro de una villa con galería y torres en la fachada, vista en perspectiva de alzado abatido, un peristilo semicircular de doce columnas, semejante a los documentados en los mosaicos de Henchir Toungar, del siglo III, el de la Carta de Madaba, del siglo vi, y en los de la mezquita de Damasco, fechados en el

H. Lavagne et alii, "La villa gallo-romaine de Près-Bas à Loupian (Hérault)". Gallia, 34 , 1976, 230-235, fig. 12 (con un detallado estudio del pavimento); Id. "Les nouvelles mosaïques de la villa gallo-romaine de Loupian (Herault)", RANarb 14, 1981. 173-174, plano, fig. 1. Recientes excavaciones arqueológicas en la villa fechan los mosaicos en el último cuarto del siglo IV, cf. M. Lu GARU y Ch. PEllecuer, "La villa des Près-Bas à Loupian (Hérault)", Actes de IXe journnées d'archéologie mérovingiennne: Gaule mérovingienne et monde méditerranéen. Lattes, 1988, 131-141. C. BALMELLE, "Les représentations darbres fruitiers sur les mosaïques tardives d'Aquitaine", VI Coloquio Internacional sobre Mosaico Antiguo (Palencia-Mérida, 1990), 1994. 267.

C. BALMEILE, op. cit. (n. 13), 261-272 (con identificación de los frutos).

A. BFN ABED, "Découverte de mosaiques romaines en Tunisie". Archéologia 139 (fév. 1980), 48-51: A. Ben Abto y A. Be SCHAOuCH, "Les mosaiques de la Maison du "Peristiyle figuré" et de ses thermes à Pupput (Hammamet) et un voeu de navigation heureuse». Fifth International Colloquinm on Ancient Mosaic (Bath, England, 1987), 1994, 175-180. 184-185, figs. 9 y 12

J. P. MtL.IDA, "Un mosaico descubierto en Toledo". Bol. de la Real Academia de la Hist. 83, 1923. 19-23; J.M. B| AzQUEZ, Mosaicos romanos de la Real Academia de la Historia, Ciudad Real, Toledo. Madrid y Cuenca, CMRE V. Madrid. 1982. 38, láms. 20-22; J.G. Gorges, “A propos d’une représentation de villa sur une mosaïque de Tolede (Espagne)". Conimbriga, 25. 1986, 183-187 láms. I, fig. 1 ; II-IIl, fig, 1 . 


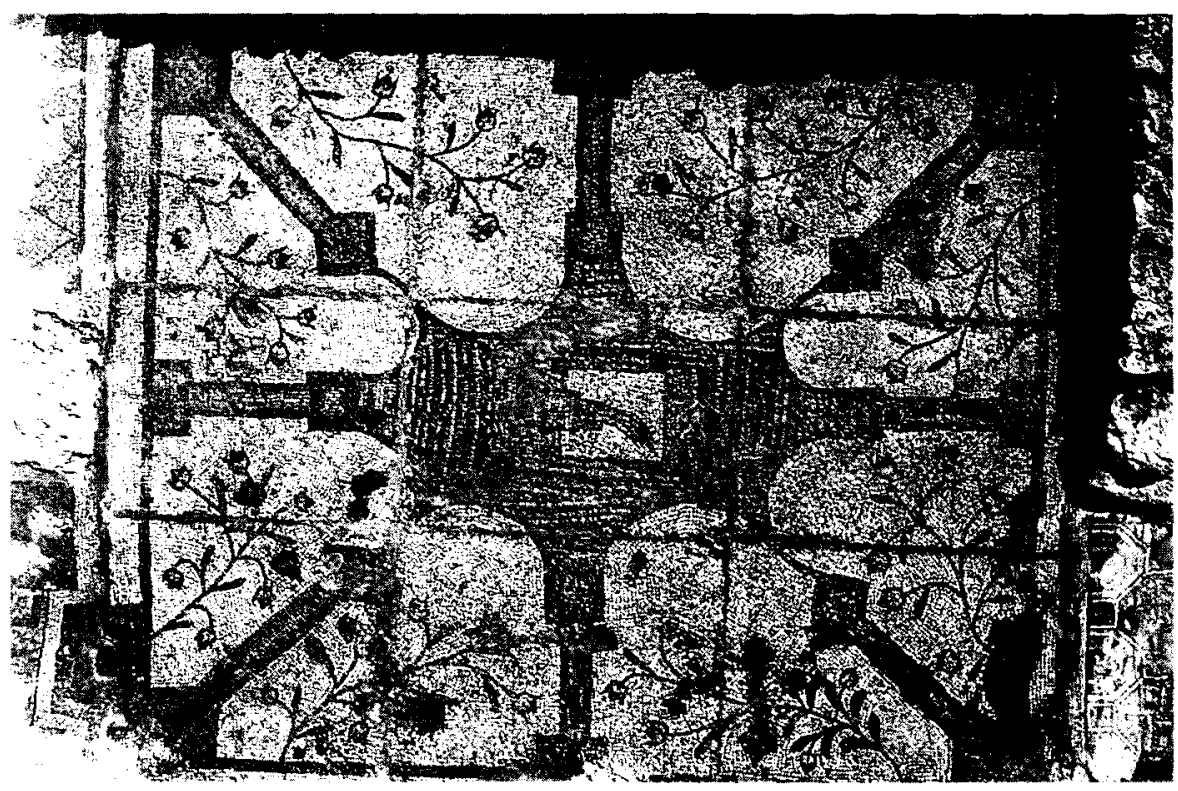

Figura 8. Mosaico de Pupput, Hammamet.

siglo vill ${ }^{17}$; modelo arquitectónico que a su vez se aprecia en la villa real de Rielves (Toledo), del siglo IV ${ }^{18}$. Lo más interesante de este pavimento es que en el centro del peristilo se ve unas líneas paralelas de teselas blancas y negras, que posiblemente corresponden a las canalizaciones de las aguas de la zona ajardinada como es habitual en las villas romanas y particularmente en las hispánicas de los siglos $1 / 1$ y IV, aunque aparecen también en las de épocas anteriores ${ }^{19}$. Por consiguiente este mosaico constituye un ejemplo unicum de la figuración de la irrigación del jardín mediante canales.

El agua junto con la vegetación que dependía de ella son el centro conceptual del jardín. El sistema más representado en los mosaicos para la actuación de las aguas son las fuentes que, además de mantener el frescor y la humedad necesarias para la conservación de las plantas, ten-

G. LOPEz MONiEAGudo, "Mapa de Madaba: centenario de su descubrimiento". Rev de Arqueología $n$ 200, dic. 1997, 51. Id., "Las ciudades representadas en el mosaico bizantino de "La Carta" de Madaba. Origen y paralelos". Espacio. Tiempo y Forma. 10. Serie II. Historia Antigua, 1997. 206-208. figs. 34 y 35

M. C. Fifinanoey Casiro, Villas romanas de España. Madrid, 1982. 111-112. figs. 53 y 54 lbidem. figs. $95-96$ 
drian una función ornamental. Se documentan tres tipos de fuentes: uno en forma de estanque rectangular, otro circular con pie alto o columna y un tercero, que es el más frecuente, en forma de crátera.

Perteneciente al primer grupo y unicum hasta el momento en la musivaria romana, aparece en el citado mosaico africano de Pupput (vid. supra), que según la interpretación de $A$. Ben Abed sería un faro, sin embargo la salida del agua a modo de surtidor y su ubicación en el centro del peristilo figurado no deja duda de su función.

El segundo tipo se representa en el citado mosaico de Pompeya (vid. supra) y en el pavimento de carácter nilótico de El Alia, conservado en el Museo de Sousse y fechado en el siglo II (ca. 120-30) (figura 9) ${ }^{20}$, que tiene grandes influencias de la iconografía helenistica ${ }^{21}$. Muestra en la parte superior y en alzado un jardín circular, describiendo un ambulatio, y una fuente con surtidor en el medio similar a las de las pinturas de Herculano y Pompeya (vid supra).

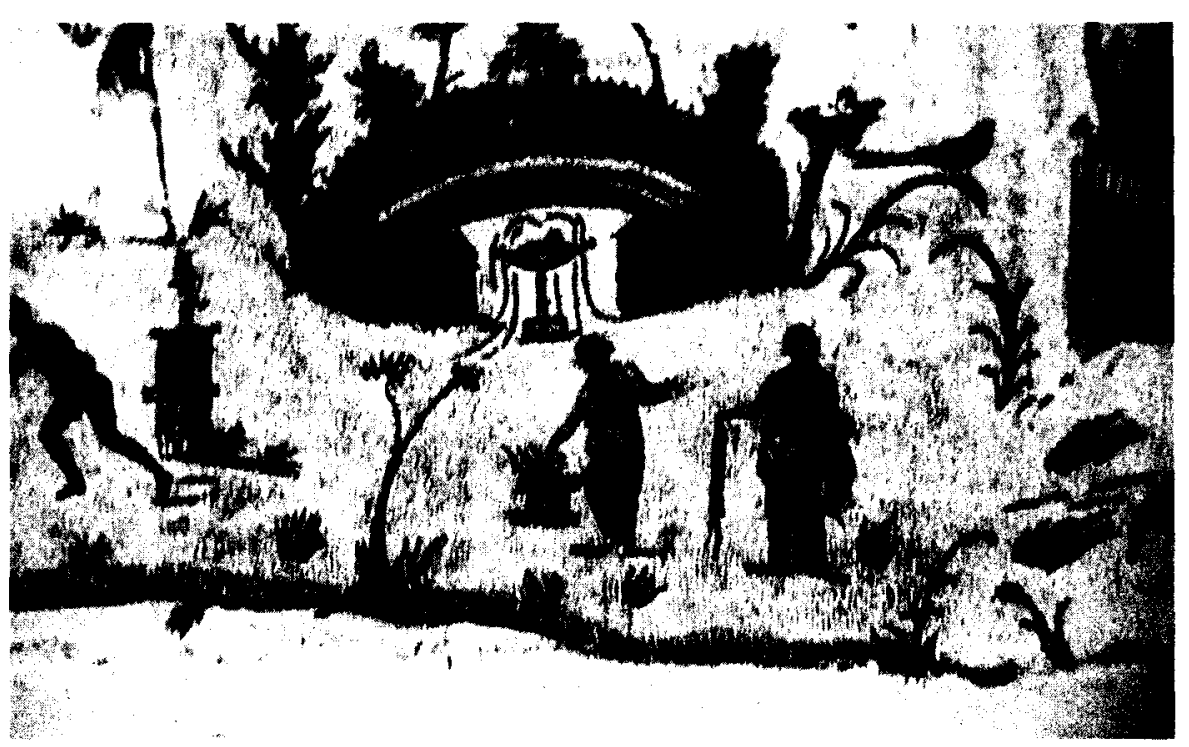

Figura 9. Mosaico de El Alia.

so Inv. Tun. 93; L. FoUCHER, “Les mosaïques nilotiques africaines», CMGR I (Paris, 1993), 1965, 138-139; K.M.D. DunfabIN, The Mosaics of Roman North Africa. Oxford, 1978, 20, 48 , 110,257 , lám. 6 .

‘) L. FOUCHER, “L'influence de la peinture hellénistique sur la mosaïque africaine au $\|$ et ॥ sie cles", Cahiers de Tunisie VII, 1959, 263-274. 
El último tipo de fuente se documenta en varios mosaicos y es también frecuente en pinturas pompeyanas ${ }^{22}$. En el pavimento de Los Gladiadores de los siglos $110 \mathrm{ll}$, procedente de la sala -oecus? - de la insula 30 de la antigua ciudad de Augusta Raurica, hoy conservado en el Museo de Augst (Suiza) ${ }^{23}$, presenta en dos de los lados de su emblemata rectangular una orla decorada con cuatro flores de forma acampanada, seguida de un espacio circular inscrito en un cuadrado cuyas esquinas están decoradas con roleos de acanto y de campánulas. En el interior del círculo, probablemente la planta de la fuente o estanque, se ha figurado, en alzado cónico, una crátera agallonada con sus asas de volutas, de la cual sale un surtidor de agua, mientras que varios peces, entre ellos un delfín, nadan a su alrededor (figura 10). La representación en el mismo pa-

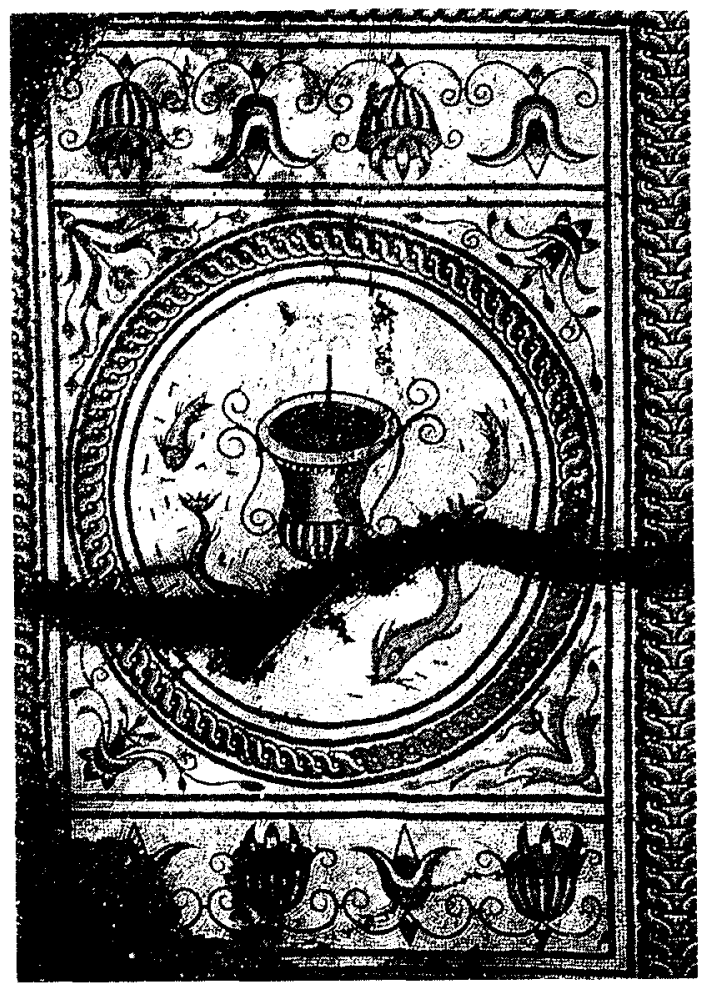

Figura 10. Mosaico de Augusta Raurica.

\footnotetext{
$\approx$ W. F. JasheMSKI (1979), op. cit. (n. 1), figs. 104 y 115.

L. BefGith y M. Joos. Das Augster Gladiatorenmosaiik. Römerhaus un Museum Augst, Augst 1971, passin.
} 
vimento de varios cuadros con diversas escenas de lucha de gladiadores podría indicar que lo que aqui se ha querido representar es el jardín urbano que estaría cerca del anfiteatro, como sería el caso del pavimento del Gran Palacio de Constantinopla, fechado en la segunda mitad del siglo $\checkmark{ }^{24}$. En él se representa junto a las puertas una palmera con dátiles y un árbol con unos pájaros volando que forman parte de la escena de circo, coincidiendo con la referencia de Vitruvio de la presencia de jardines en torno a los circos $(\mathrm{V} 9,5)$. La misma identificación la encontramos en el muy destruido mosaico de Venatio de la villa de El Reguer (Puigvert de Agramunt, Lérida), fechado en el último cuarto del siglo IV, cuya orla está decorada con hojas de acanto y cráteras con ramos de laurel ${ }^{25}$.

Otra crátera agallonada similar a la de Augusta Raurica, se documenta en el mosaico hispano de El Vilet (Lérida), de finales del siglo III o comienzos del iv ${ }^{26}$. Aqui los peces aparecen en el interior del vaso que está franqueado por dos palomas posadas en las asas y por guirnaldas de rosas que picotean otras cuatro aves (figura 11). La asociación de las pa-

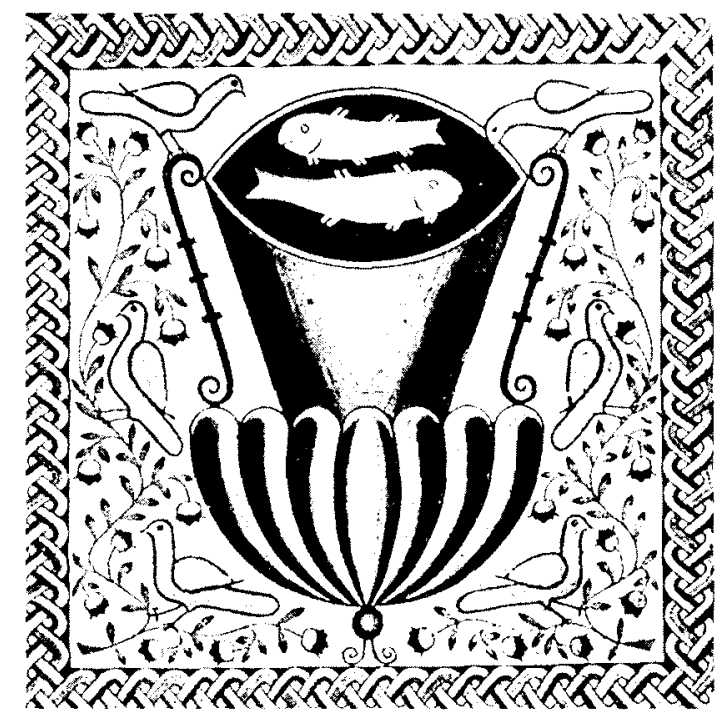

Figura 11. Mosaico de El Vilet, Lérida.

4 G. Brett et alii. The Great Palace of the Bizantine empeors. Oxford, 1949. 69-70, láms. 2930: G. Ht. I I NKt MPI R SAl is S. "Die Datierung der Mosaiken im Grossen Palast zu Konstantinopel”. Bjb 87, 1987, 308

J.M. BI AzQUJ $/$ et alii, Mosaicos romanos de Lérida y Albacete. CMRE IX. Madrid. 1989, 20 21. n 20, láms. 7 y 8 .

Ibidem. 23-24, n 24. lám. 9 
lomas con la crátera aparece en un mosaico de la Villa de Adriano ${ }^{27}$, que reproduce la célebre obra pictórica, del siglo I a. C., "Palomas bebiendo" de Sosos de Pérgamo descrita por Plinio (Hist. Nat. XXXVI 61).

En el mosaico de la villa de Artieda de Aragón (Zaragoza), de fines del siglo IV o comienzos del $v$, procedente de una de las habitaciones dispuestas a un peristilo ${ }^{28}$, muestra en su emblemata cuadrado una gran crátera con pequeñas asas de volutas, de la que brota un tallo verde como la de la pintura pompeyana de la Casa de Venus Marina, y está franqueada por dos pavos reales (vid. supra). En la boca de la crátera aparecen trazos en forma de zig-zag, simulando agua, que aparece asimismo en el exterior del vaso indicando el espacio de la fuente, junto a ella plantas, posiblementes acuáticas; en la parte baja, dos faisanes (figura 12), como en la pintura de Pompeya $(1,6,13)$.

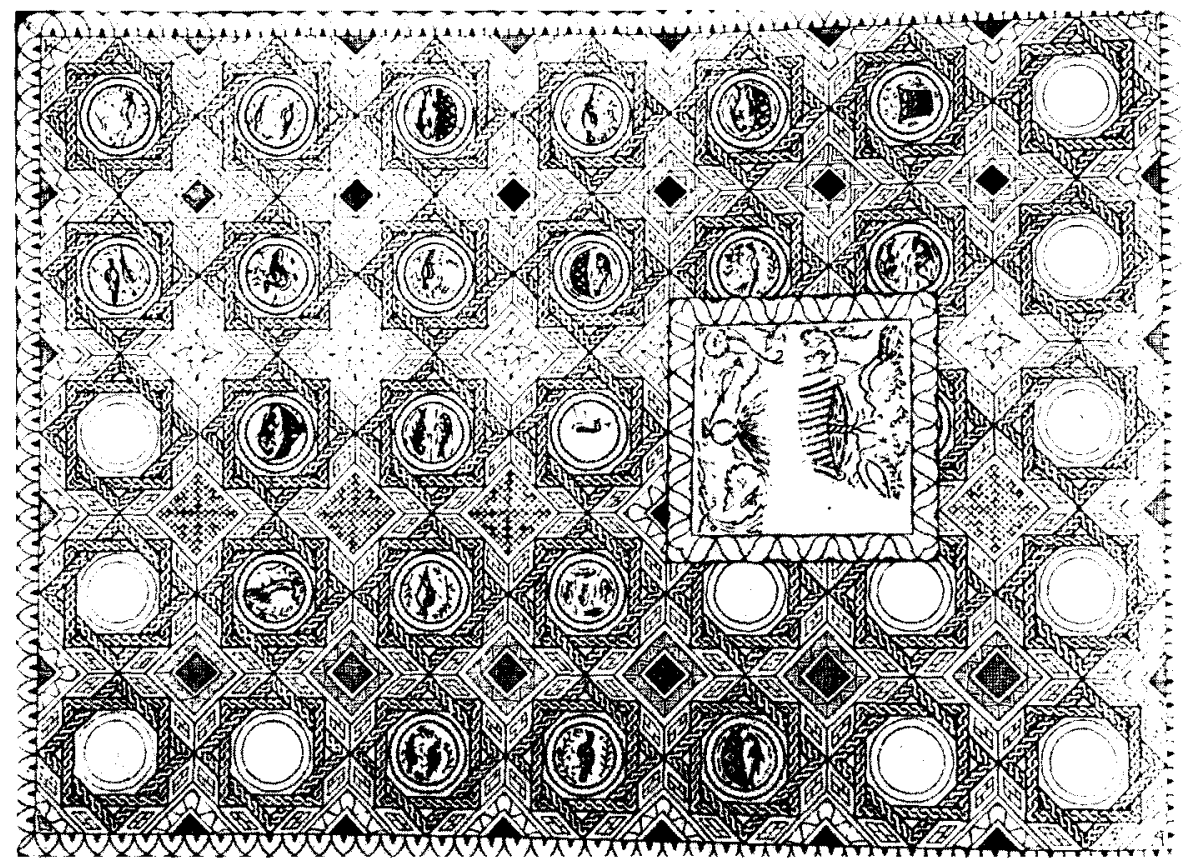

Figura 12. Mosaico de Artieda de Aragón, Zaragoza.

P. Gusman, La villa impériale de Tibur. Paris, 1908, 220. lám. II

D. Firhandr / Gal iano. Mosaicos romanos del Convento Caesaraugusto. Zaragoza, 1987 29-31, lám. Xl. 
Fuentes cumpliendo también una función ornamental en una zona verde, representadas en perspectiva cónica, aparecen en un fragmento del mosaico de Burdeos, procedente de una lujosa domus, de finales del siglo $\mathrm{V}$, que ha sido reconstruido por Balmelle ${ }^{29}$. Presentaría en los lados del rectángulo dos cestos de frutos encuadrando un árbol frutal (peras y manzanas), y en las esquinas, alternativamente, una crátera de la que sale una pirámide vegetal y una fuente, en forma de crátera agallonada y con surtidor de agua, franqueada por dos delfines y dos palomas. Todo ello estaría encuadrado por una guirnalda de laurel, en cuya esquina conservada se aprecia cuatro cráteras en diagonal con la función de realzar la belleza del espacio (figura 13). Una composición similar pero a base de cráteras con pirámides vegetales dispuestas en los cuatro ángulos y encuadrada por una franja de cornucopiae, aparecía en el perdido mosaico de Sarbazan (Landes), de la misma fecha ${ }^{30}$.

El mosaico de Saint Remy-la Varenne (Francia), de la misma fecha que los anteriores, del que se conserva solamente un fragmento y co-

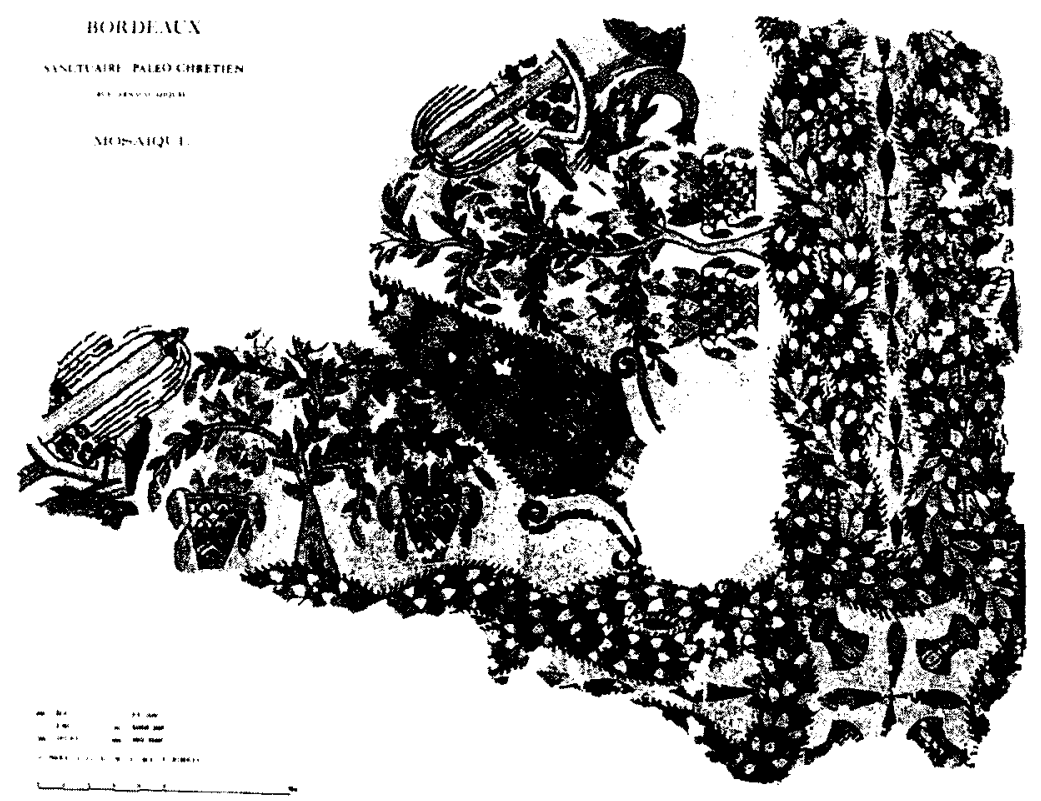

Figura 13. Mosaico de Burdeos.

C. BALmel.11. op. cit. (n. 13). 265, fig. 5 .

1d. RecMosGaule IV. 2, n 249: /d, op. cit. (n. 13), 263, fig. 4 
nocida su composición por un antiguo dibujo ${ }^{31}$, muestra en los ángulos del cuadrado también cráteras con conos vegetales y en los lados una arcada interpretada como el cenador que delimitaría el jardín. En el interior se representa un rectángulo, posiblemente el estanque que recogería el agua de la lluvia con la que regar el jardín (Palladio I, XXXIV, 2) (figura 14).

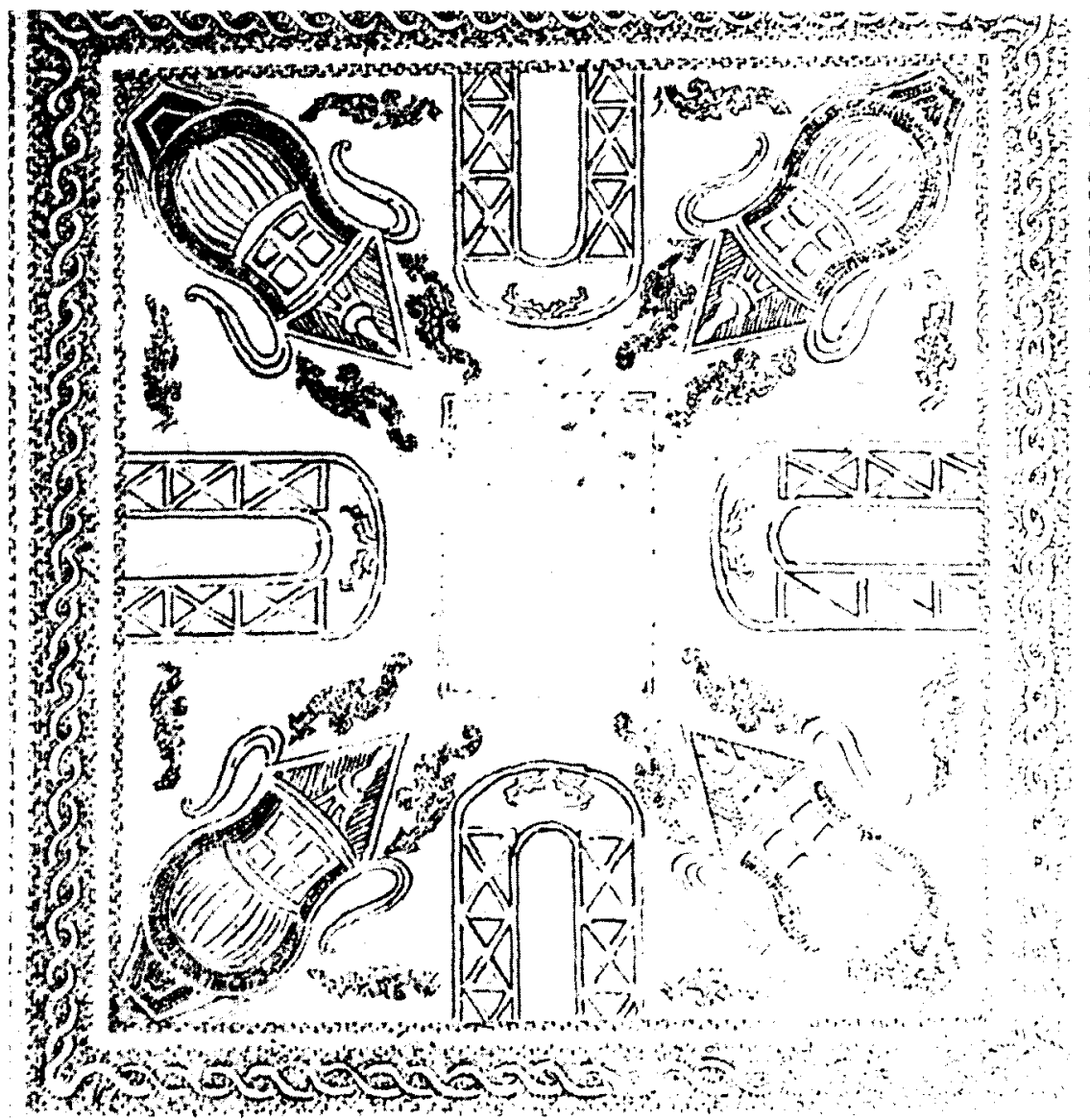

Figura 14. Mosaico de Saint Remy-la Varenne.

M. Blancharo-LemeE. "Mosaïques tardives et survie des villas en Gaule Moyenne à l'époque Mérovingienne». Mosaique. Recueil d'Hommages à Henri Stern (Paris. 19831, 78-79. lám. LI. $1-2$. 
Espacios ajardinados estructurados con cráteras de las que salen en diagonal plantas talladas en pirámides o conos (metulae), propias del jardín clásico (Plinio Epist. V 6, 35), se documentan, además de la Galia (vid. supra), en la musivaria norteafricana, baste citar el pavimento del oecus de la Casa del Peristilo de Pupput, del siglo v ${ }^{32}$. Está constituido por un gran cuadrado central y cuatro pequeños a los lados cubiertos de rosas, de los que se conservan solamente dos. El cuadro central está formado alternativamente por ocho veneras y ocho cráteras agallonadas con conos de hojas de laurel, y entre ellas volutas de acanto. En el centro, dentro de un octógono, se ha figurado una crátera con palomas posadas en su abertura y ramas de vid con hojas estilizadas (figura 15). El mosaico de Cartago, que se conserva en el Museo de El Bardo, datado en el siglo $\vee$ o $v^{33}$, donde figuran, en torno a las cráteras, hojas de acanto con pájaros, legumbres y frutos. El mosaico del oecus de la Casa de Nicentius en Thuburbo Majus, de finales del siglo $1{ }^{34}{ }^{34}$, decorado por nueve compartimentos, de los que se

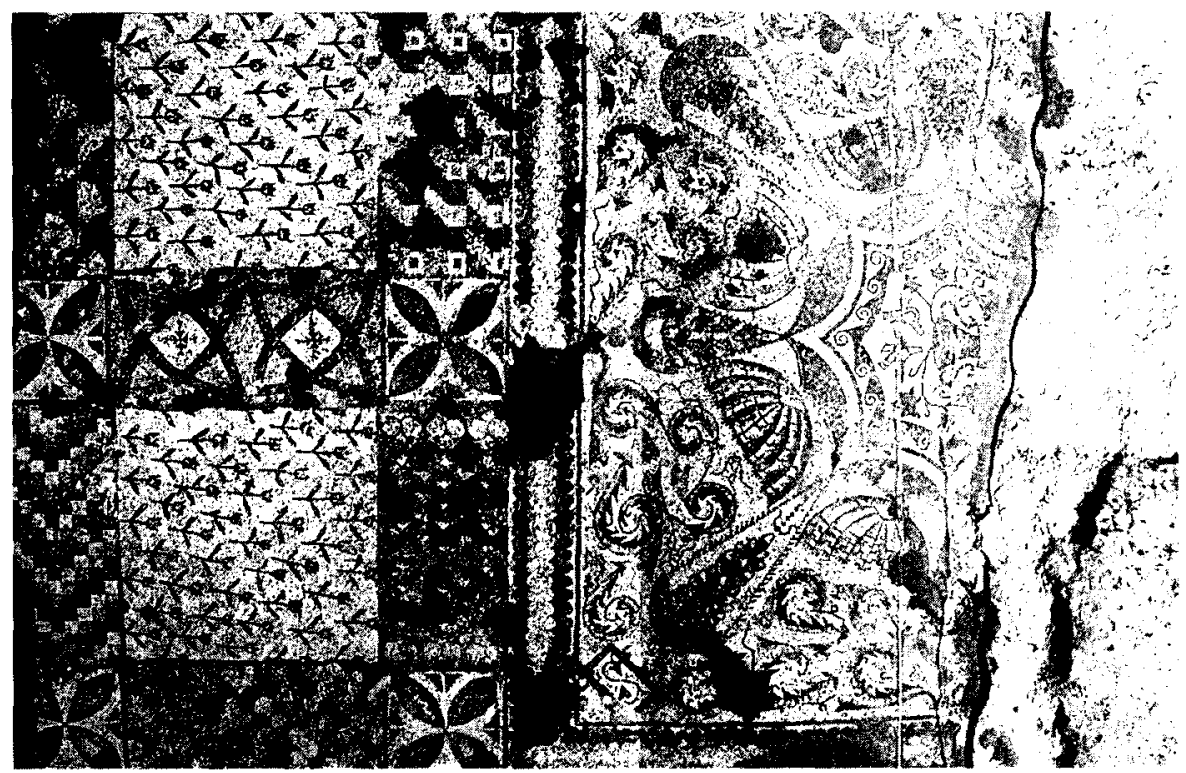

Figura 15. Mosaico de Pupput. Hammamet.

A. BFN ABED, "Une mosaique à pyramides végétales de Pupput". Mosaïque. Recueil d' hommages à Henri Stern (París, 1983), 61-64; A. BEN Alze D y A. BesCHAOuch, op cit (n. 15), 175, fig. 5.

W. Bin OSMAN, "Mosaiques a Xenia de Carthage", en Recherches Franco-Tunisiennes sur la Mosaïques de l'Afrique. Antique-I Xenia, 1990, 49, fig. 48.

Corpus des Mosaiques de Tunisie II. 1. Thuburbo Majus. Túnez. 1980, 47-49, n' 40A. láms. $X X-X X 1$. 
conservan ocho, separados por una guirnalda de laurel. En cada uno de los compartimentos se alternan cuatro veneras y cuatro cráteras con conos vegetales; en el centro del cuadrado aparecen diferentes motivos geométricos (figura 16). En Hispania, el mismo motivo de pirámides vegetales

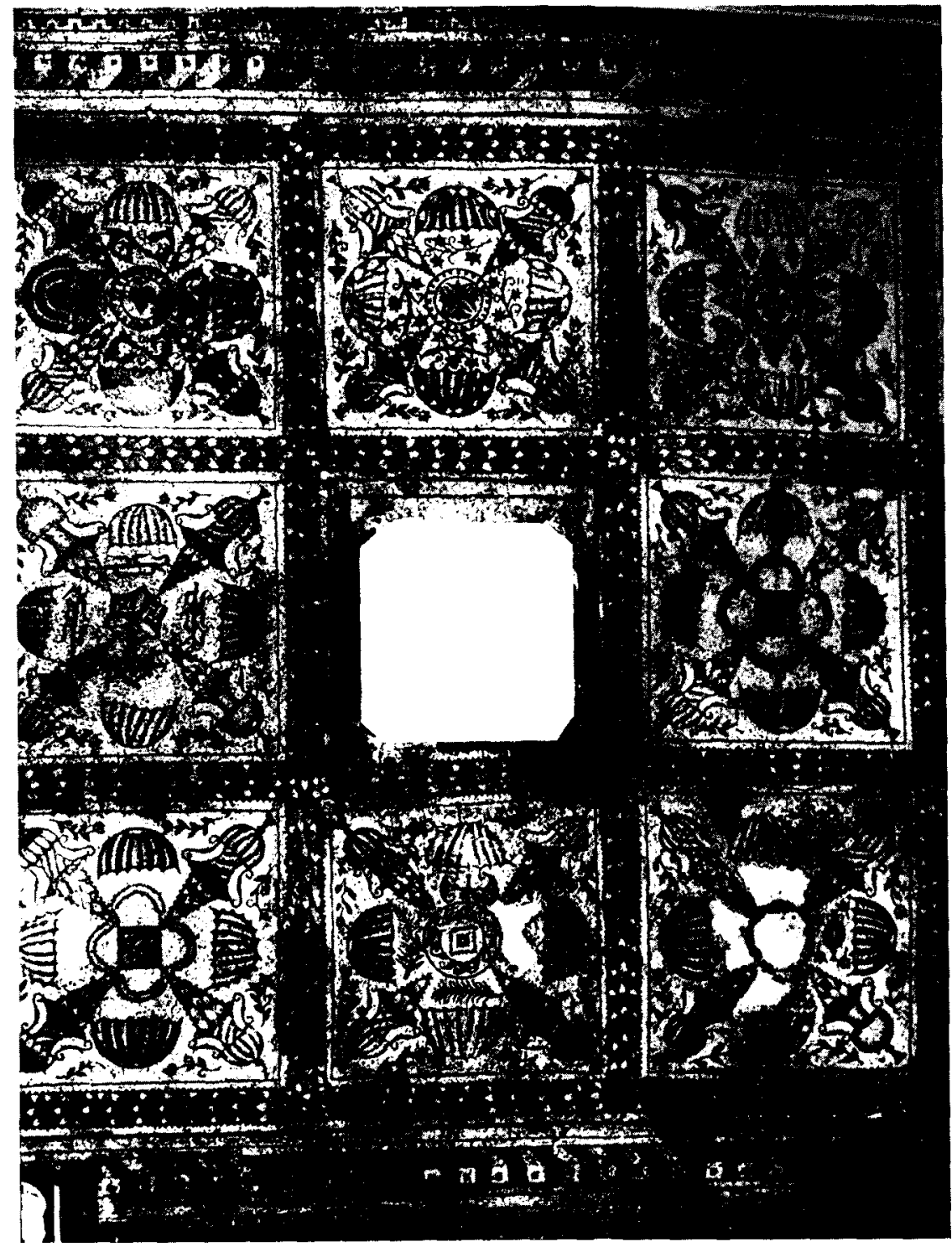

Figura 16. Mosaico de Thuburbo Majus 
aparece en el mosaico de la Basílica de Illeta del Rey, en Mahón, del siglo IV ${ }^{35}$. Con cráteras en los ángulos en el citado pavimento de la villa de El Reguert en Lérida (vid. supra); en el mosaico de la villa de Prado (Valladolid), fechado en la segunda mitad del siglo $\mathrm{IV}$, que procedía de una de las habitaciones del ala norte del peristilo ${ }^{36}$. En él destacan dos guirnaldas de laurel dispuestas en arco, cuyos extremos surgen de la boca de las cuatro cráteras de los ángulos, que podrían figurar la pérgola (figura 17). El

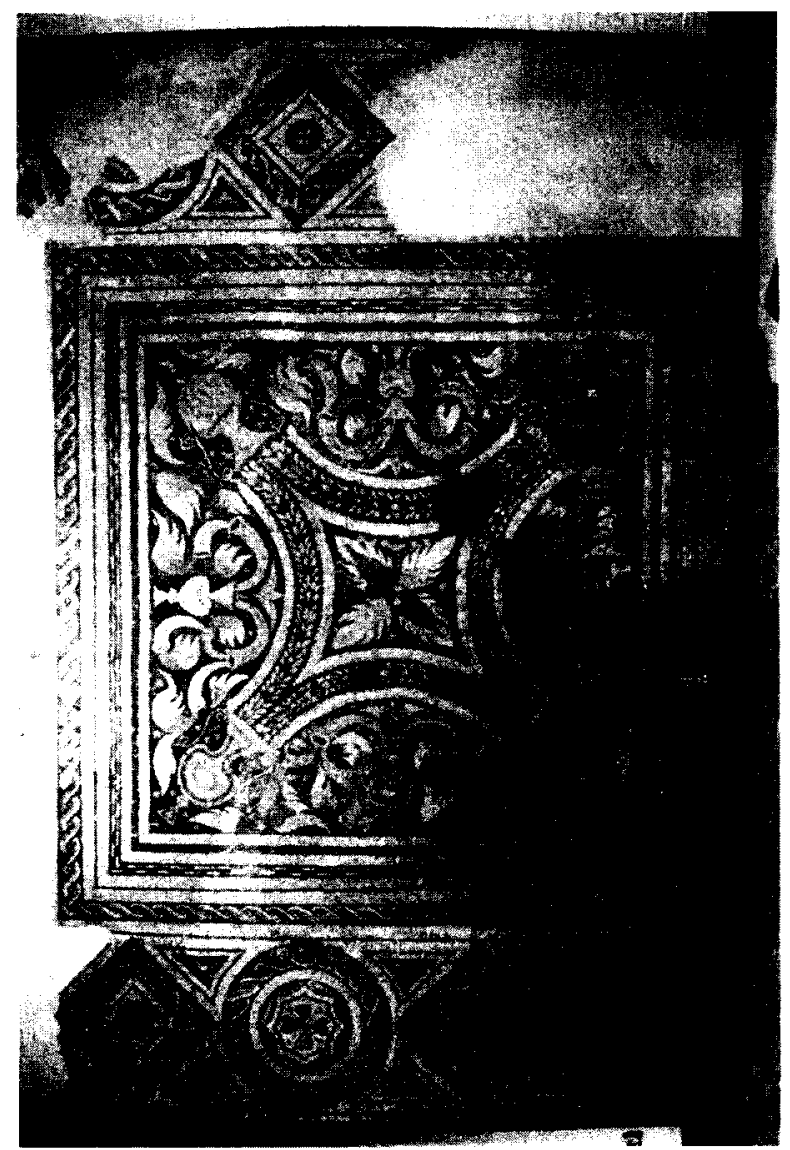

Figura 17. Mosaico de la Villa de Prado, Valladolid.

34 P. PALOL, Arqueología cristiana de España romana. Madrid, 1967, 229-230, lám. XLVI-L.

se. M. TORREs CARRO, "Los mosaicos de la Villa de Prado (Valladolid), BSAA 54, 1988, 181191, fig. 3. láms. Il y III: L. NEIRA y T. MAÑAnES, Mosaicos Romanos de Valladolid, CMRE XI. Madrid, 1998. 53-56, n 22, fig. 10, láms. 20-21 y 39. 
mosaico de la villa de Liédena (Navarra), fechado a principios del siglo $v^{37}$, muestra en el emblemata central jarros sin asas colocados en los ángulos, y a los lados, alternativamente, tallos con hojas y palomas; en el interior dos círculos concéntricos encuadrados por una guirnalda de hojas de laurel (figura 18).

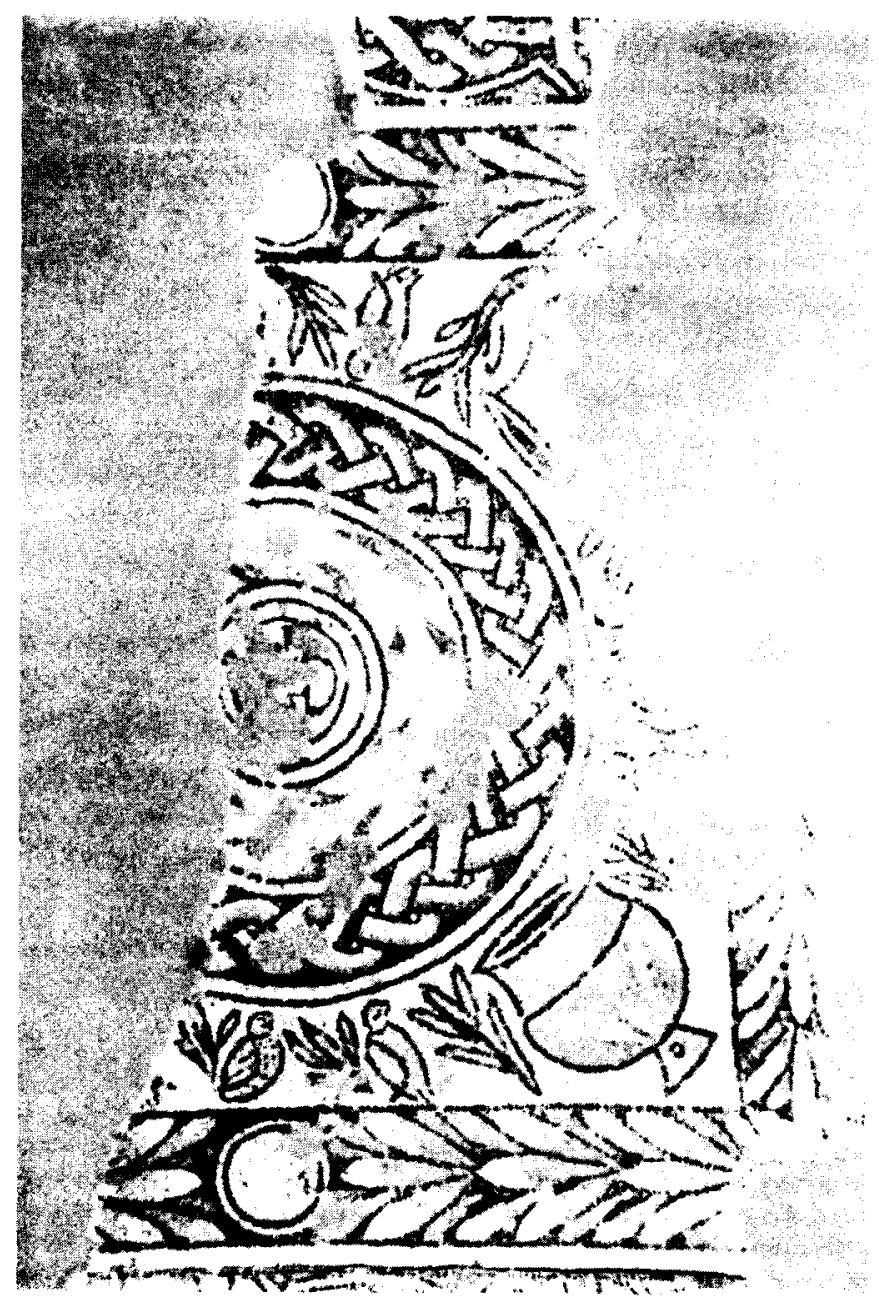

Figura 18. Mosaico de Liédena, Navarra.

J.M. Bi AzQUFz y M.A. Mt Zoulal?, Mosaicos Romanos de Navarra, CMRE VII. Madrid, 1985. 48-49, n" 25, lám. 30: D. Fernand 7-Galiano, op. cit. (n. 28), 118, n 187, lám. Lì 1 
Otro recurso utilizado para figurar la zona ajardinada es cubrir el espacio con motivos florales distribuidos libremente, como se documenta en los cuadrados laterales del citado pavimento del oecus de Pupput (vid. supra) o el de la habitación XIII de la misma Casa, ambos con tallos de rosas aislados ${ }^{38}$; en el de Cherchel con follaje y flores de color blanco, rosa y ocre, algunas de campánula, dando la sensación como si fueran plantas trepadoras, similar a las figuradas en las pinturas pompeyanas ${ }^{39}$ (figura 19); en el de la villa de EI Romeral (Lérida), del último cuarto del siglo IV, con ramas, hojas y palomas ${ }^{40}$; $y$ en el mosaico del espacio entre el pasillo del peristilo y el viridarium de la Casa de Volière en Cartago, de la misma fecha que el anterior ${ }^{41}$; con una decoración de diversos animales, plantas con frutos (man-

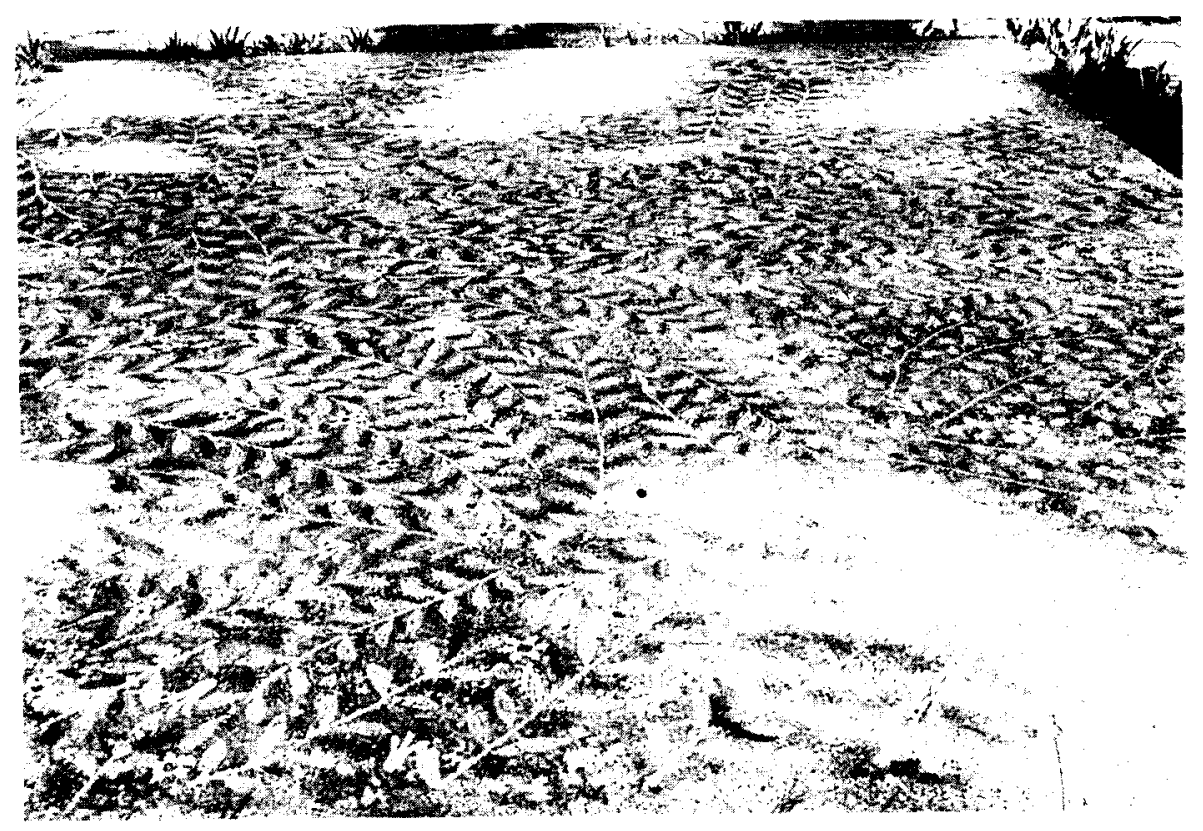

Figura 19. Mosaico de Cherchel. Foto G. López Monteagudo.

A. Ben Abed y A. Beschaouch, op. cit. (n. 15), 175, fig. 3

$S$. FERDI, "Les Mosaïques de la Maison de la Jonchée à Cherchel», Vllème. Colloque International pour l'étude de Mosaïque Antique (Túnez, 1994), en prensa.

J.M. Bi AzQuez et alli, op. cit. (n. 25), 17-18, láms. 5, 21 y 22

Inv. Tun. 640; 1. Lavin, "Antioch Hunting Mosaic and their sources" DOP 17, 1963, 213, figs. 31-33: K.M. D. Dunbabin. op. cit. (n. 20), 125, n. 58, 167; S. Germain, "Logique et fantaisie dans les Mosaïques de jonchée", Antiquités Africaines 14, 1979, 171; R. FARIOLI, "Étude des pavements de la villa de la Volière"., Mosaique. Recueil d'Hommage à Henri Stern (Paris, 1983), 147148, láms. LXXXIV-LXXXVII. 
zano, granado, ciruelo, limonero, olivo, peral, cidro...) y flores (alheli, rosa, margarita, lis, jasmín, clavel...), que evocan un suntuoso jardín (figura 20).

Plantas, flores y aves dentro de una composición de arcadas cubriendo toda la superficie se encuentran en algunos mosaicos también del Bajo Imperio como son entre otros el de El Romeral (Lérida) o el de El Val (Al-

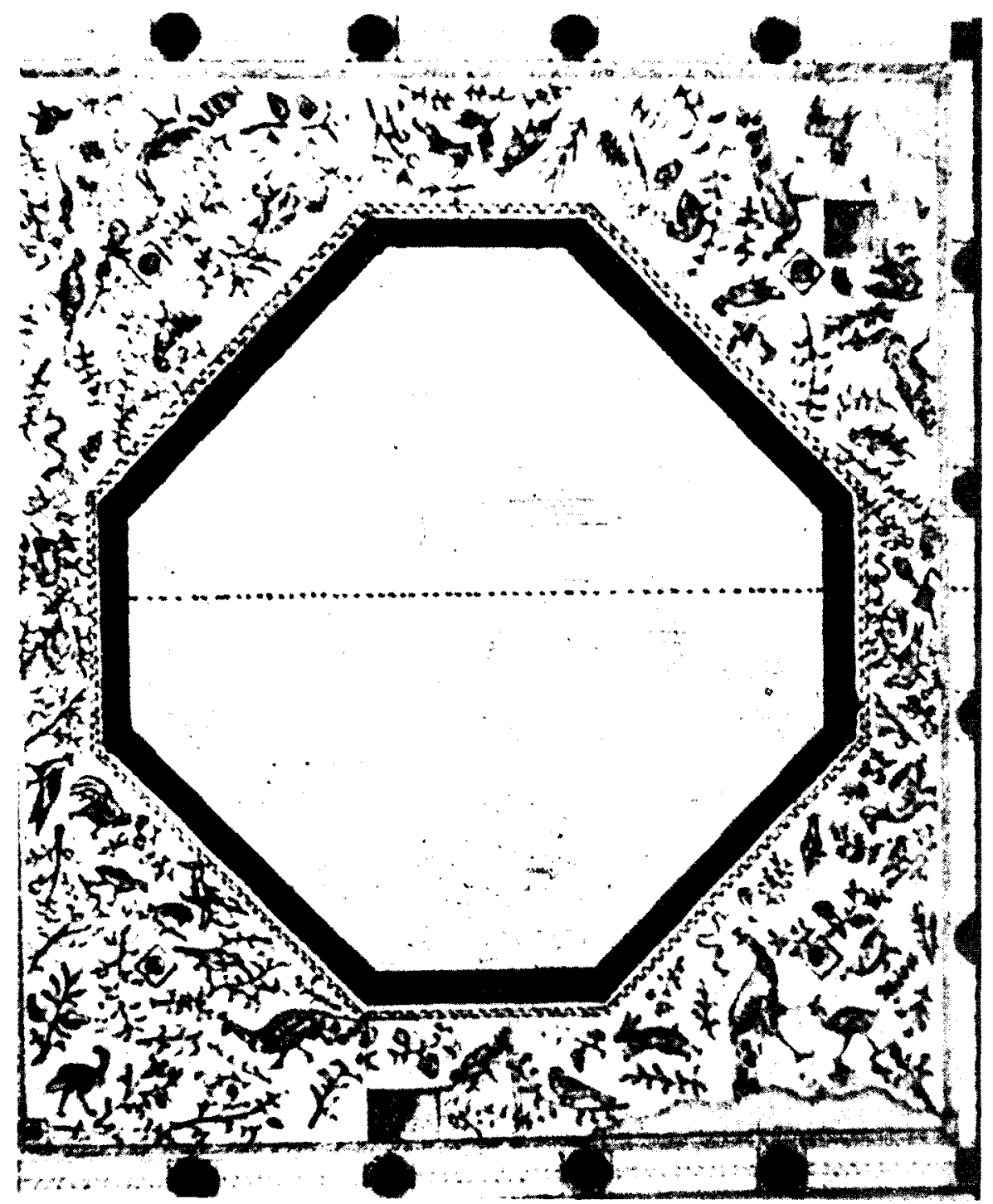

Figura 20. Mosaico de Volière. Cartago. 
calá de Henares) ${ }^{42}$ (figura 21); Lescar ${ }^{43}$ y Gárgoles (Guadalajara) ${ }^{44}$, ambos con ramos de tres hojitas; Thuburbo Majus con hojas de acanto ${ }^{45}$; Djebel Oust, con rosas ${ }^{46}$; Albalate de Cinca (Huesca), con hojas y capullos florales ${ }^{47}$. De guirnaldas de laurel entrelazadas como en el mosaico del vestibulum de la villa de El Ramalete (Navarra), con granadas, manzanas, peras y un pez ${ }^{48}$ (figura 22). Con ramos debajo de las arcadas que brotan cráteras y con ramos terminados en flor se documentan en otro mosaico de las termas de Djebel Oust ${ }^{49}$ y en otros pavimentos de Thuburbo Majus ${ }^{50}$. En el pavimento del triclinium de la villa de Torre de

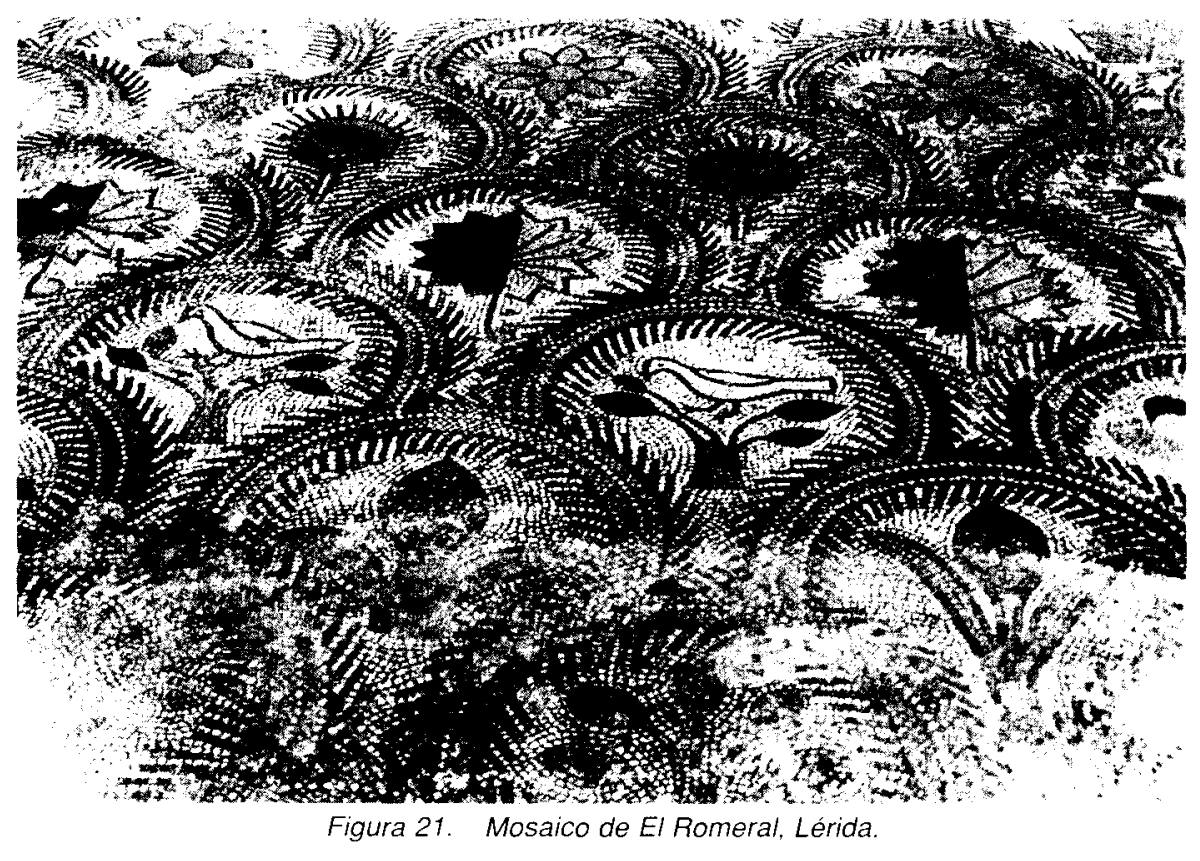

J.M. BLAZQUEZ et alii. op. cit. (n. 25), 14-15, láms. 1, 2 y 20: S. RASCON ef alli, "La villa hispanorromana de El Val (Complutum). Alcalá de Henares, Madrid", en Actas del Congreso Intern. sobre La Hispania de Teodosio (Segovia, 1995), vol. 2, 1997, 670-672.

C. Balmelle, RecMosGaule IV, 1, 142-143, n 137, lám. LXXVII.

D. Fernande- Z-Galiano, op. cit. (n. 28), 20-22, láms. $\vee$ y VI.

A. Ben ABd Ben Khader, Thuburbo Majus. Les mosaïques dans la region ouest. Túnez, 1987, 2-16, láms. V-Vill.

M. FENDRl, "Evolution chronologique et stylistique d'un ensemble de mosaïques dans una station thermale à Djebel Oust (Tunisie), CMGR I, 19, 167, fig. 12

D. Fernandez-Gal.iano, op. cit. (n. 28), 62-63, lám. XXIX.

J.M. Blazouez y M.A. MEZQUiRIz, op. cit. (n. 37), 62, fig. 9, lám. 55.

M. FENORI, op. cit. (n. 46), 162-163, fig. 4.

M.A. Alt Xander et alii. Thuburbo Majus. Les Mosaïques de la region du forum. Túnez, 1980, 40 46-47, lám XVIII, 38B: 149, láms. LIX y LXXIII, 119A: A. BEN ABED, op. cit. (n. 45), 39, lám. XVI. $272 \mathrm{C}$. 


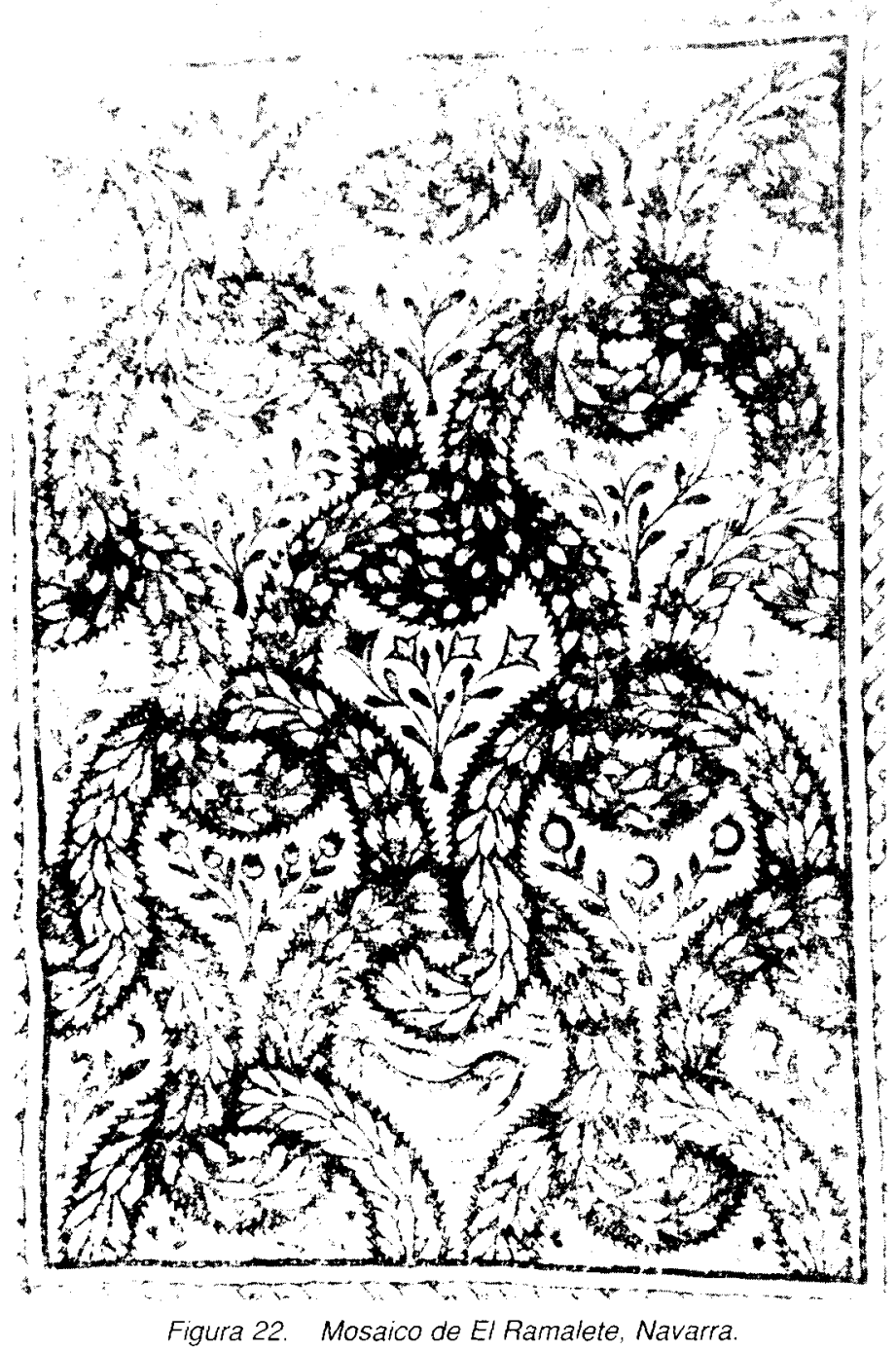

Palma esta misma decoración aparece bordeando el emblemata con restos de una figura recostada que según Heleno se trataría de una divinidad $^{51}$ (figura 23). A veces en esta decoración se sustituyen los ramos por

M. HEIENO. "A villa lusitano-romana de Torre de Palma Monforte". O Arqueólogo português IV, 1962, 333-334, láms. XIX-XX: J.M. BLAZOUEZ, «Los mosaicos romanos de Torre de Palma (Monforte, Portugal)". AEspA 52, 1979, 144-148, fig. 18 


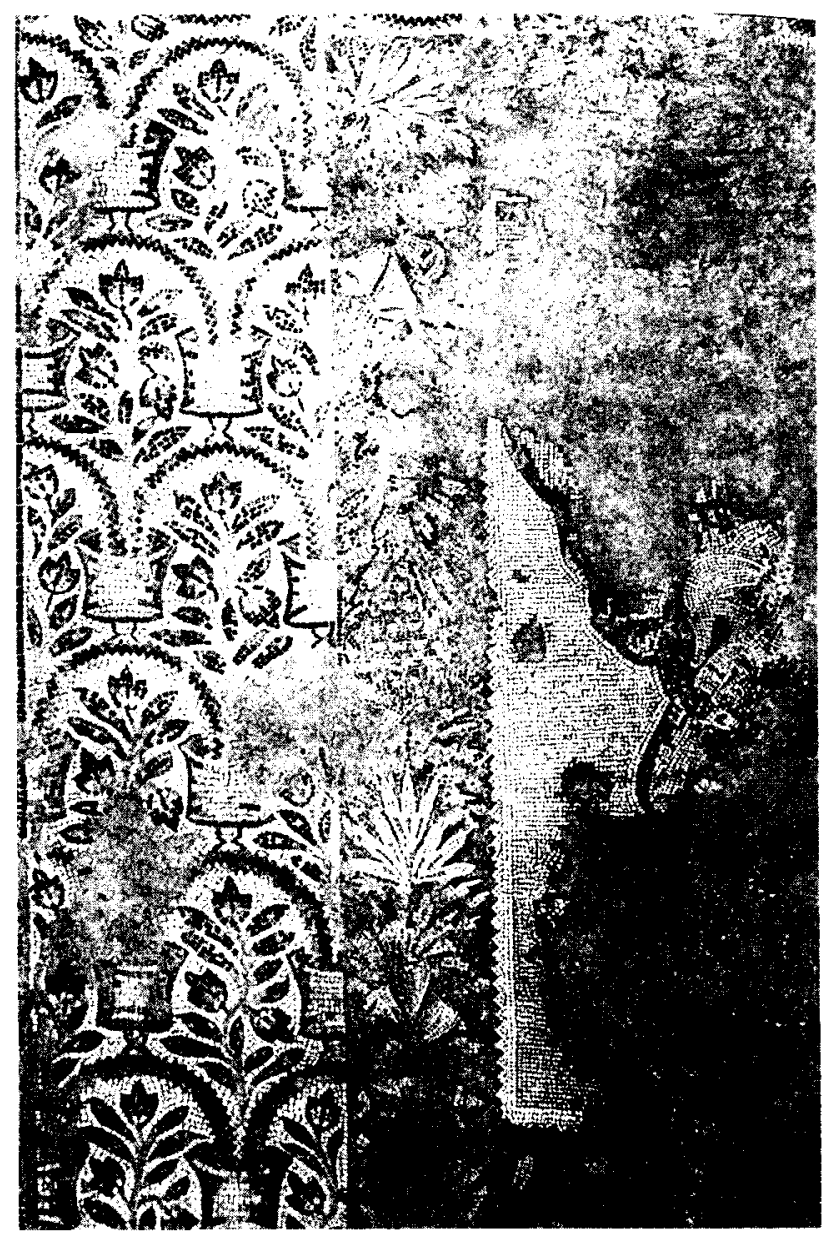

Figura 23. Mosaico de Torre de Palma. Portugal.

plumas de pavo real como presentan algunos mosaicos norteafricanos de los siglos II y III, como Soussa, Dar Zmela, Uzzita y El Jem, estos últimos sin cráteras ${ }^{52}$ (figura 24), motivo que perdura en mosaicos bizantinos de

L. Foucht.ł. La maison des masques à Sousse. Fouilles, 1962-1963. Túnez, 1965, 57 ss. figs. 80-86; G. Fradien et alii. Mosaïques de Tunisie. Túnez, 1976, 150; K.M.D. Dunbabin. op. cit. (n. 20). 167, n 168, lám. 169. M. B ANCHAFil-LEMte el alii. Sols de l'Afrique romaine. Mosaique de Tunisie. París, 1995, fig. 199. Para el desarrollo de este motivo cf. C. BAlmell f et alli. op. cit. ( $\mathrm{n}$. 10), láms. 215-216. Arcadas sin delimitar con una serie alternativa de flores estilizadas y rosetas aparece en la Casa de Beribboned Lion en Antioquía. ct. D. Lt. vi. Antioch Mosaic Pavements. Princeton, 1947, 313, lám. CXXVII. 


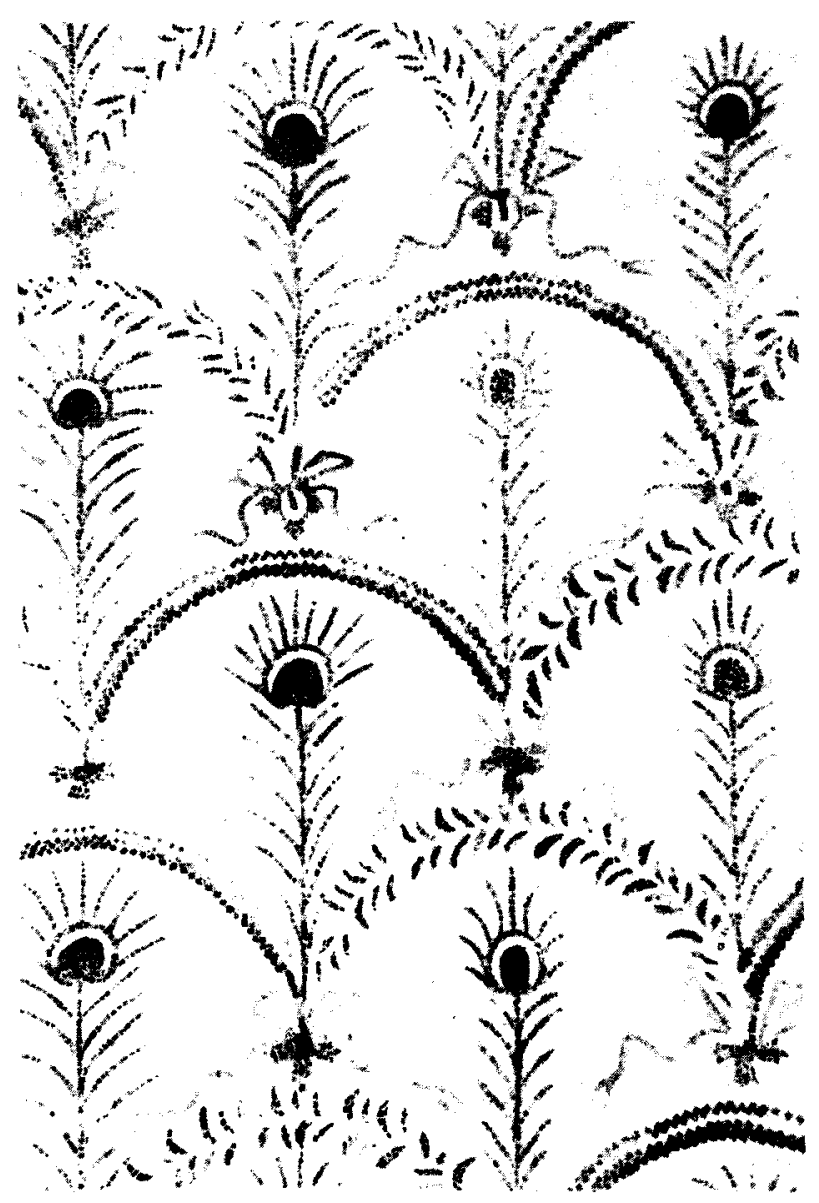

Figura 24. Mosaico de El Jem.

los sigios IV-VI (figura 25). La composición de arcadas con motivos florąles existe ya en el siglo I en manifestaciones pictóricas de Pompeya, como representación de un cancel, goza de una amplia difusión en el arte romano y perdura como decoración en las iglesias paleocristianas y visigodas ${ }^{53}$.

Seguramente todas estas representaciones figuran jardines, que en muchas ocasiones estaban presididos por el dios de la vegetación, Príapo como se ve en el mosaico de la Bobadilla (Málaga), de la primera mitad

F. WIAIH, Römische Wandmalerei. Berlin, 1934, 33, fig. 7: M.C. VII LAi ON. Mérida visigoda. La escultura arquitectonica y litúrgica. Badajoz, 1995. 327, números 115, 148 .. 


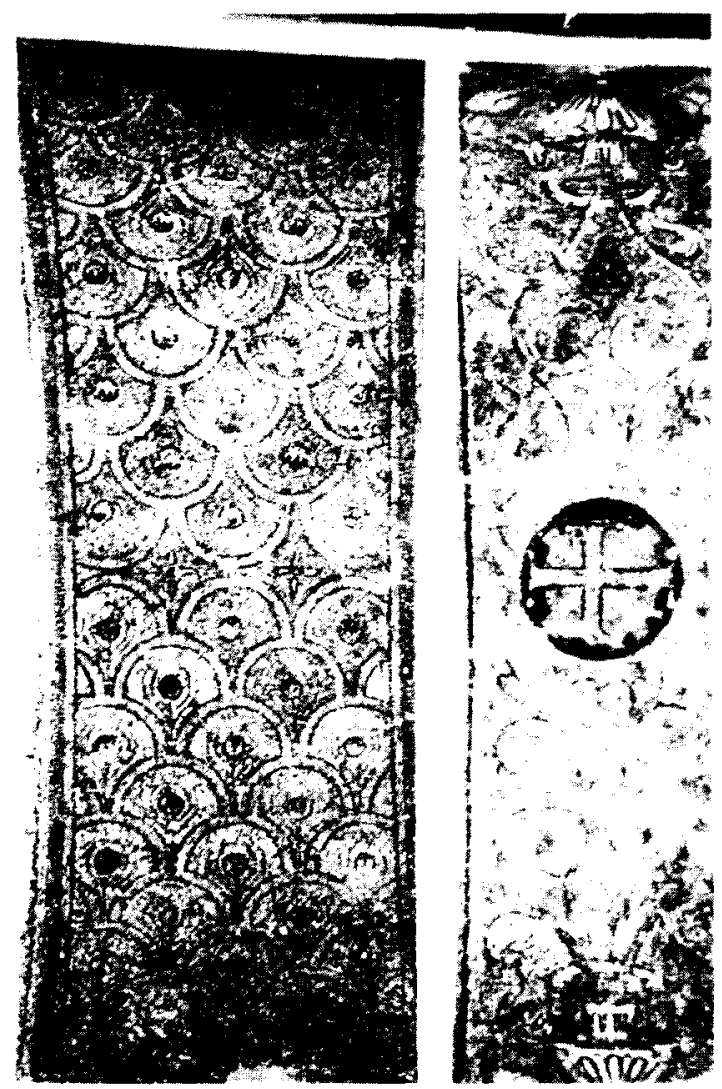

Figura 25. Mosaico de Salónica. Iglesia Achiropiitos.

del siglo III, que evoca los versos de Virgilio (Georg IV 105 ss.) ${ }^{54}$. En el cuadro central aparece el dios en pie y frontal, hijo de la diosa Venus, rodeado de flores, dos aves y plantae pedum; viste un corto chitón, que levanta con ambas manos lleno de flores y frutos y mostrando su desmesurado atributo sexual (figura 26). Paralelos para esta imagen itifálica, además de las representadas en escultura y pintura ${ }^{55}$, aparecen en dos pavimentos tunecinos, formando parte de paisajes rurales. Uno de ellos es el citado mosaico de estilo alejandrino de El Alia (vid. supra), en donde se

54 P. Rodriguf z Oliva, Mosaicos romanos de Bobadilla (Málaga). Málaga, 1987, 39-79; idem, "Los mosaicos de la villa romana de La Bobadilla (Málaga)", BSAA LIV, 1988. 137-SS.; G. LOPEZ MonieAgudo et alli, "Recientes hallazgos de mosaicos figurados en Hispania», Vllème. Colloque International pour l'étude de Mosaïque Antique (Túnez, 1994), en prensa.

h. Henter, De Priapo. Giessen, 1932, passin. 


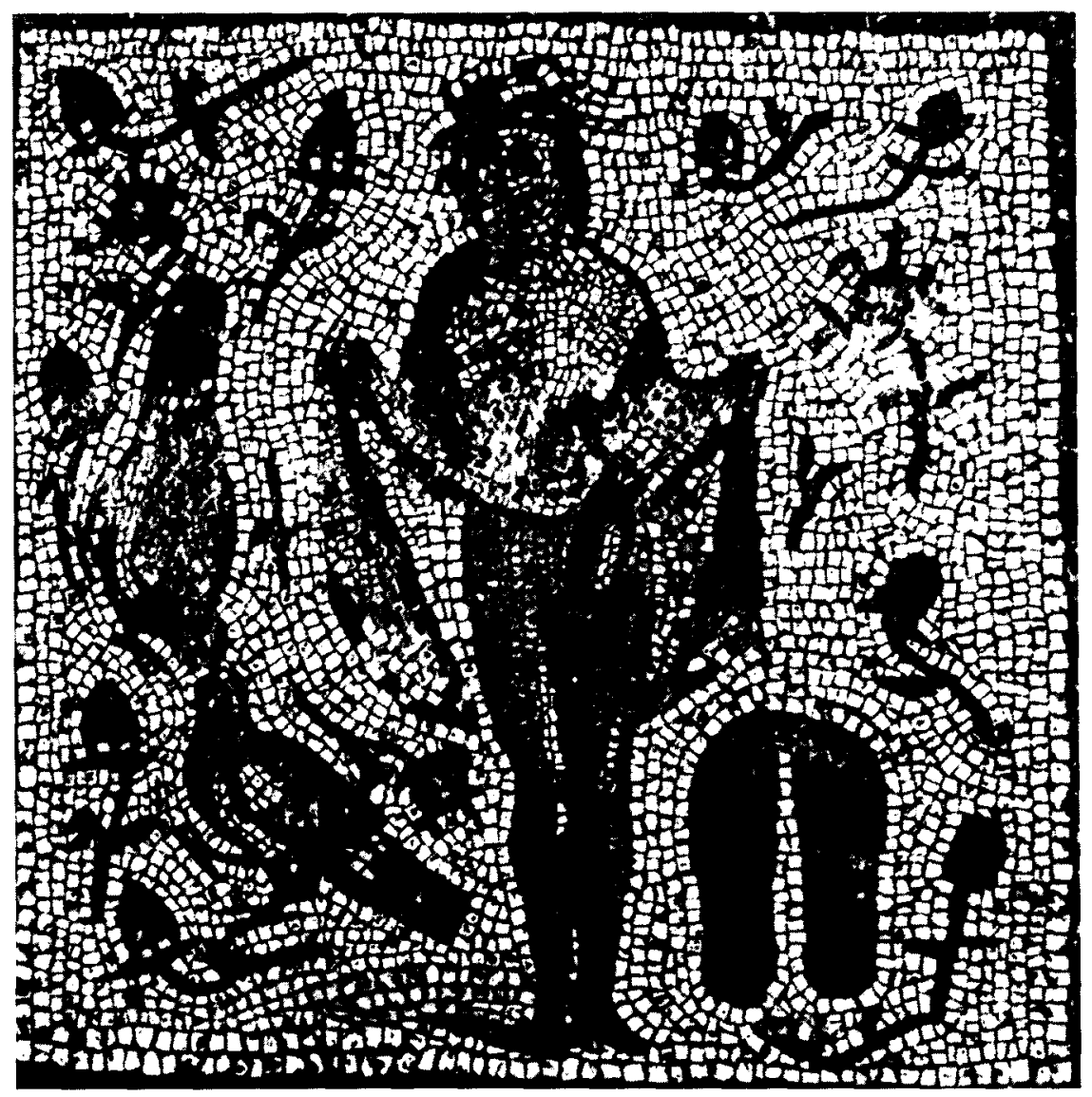

Figura 26. Mosaico de la Bobadilla, Málaga.

distingue al dios sobre un ara y al lado un hombre adiestrando un macho cabrío que se resiste ${ }^{56}$. El otro mosaico procede de El Jem, datado en el siglo IV, en él figura Príapo también sobre un ara pero dentro de un contexto dionisiaco ${ }^{5}$ ?

En uno de los semicírculos del mosaico de la Vega Baja de Toledo aparece el jardín de la villa, cuya imagen figura en el otro semicirculo citado (vid. supra), donde aparece el dominus acompañado de otras tres figuras, tal vez sus familiares o siervos. En los extremos dos edificios, el de

L. Folcher, "Priape ithyphalique». Karthago VII, 1956. lám. I. fig. 4

Idem, "A propos d'images dionysiaques», BCTH, 10-11, 1974-75, if, fig. 3 


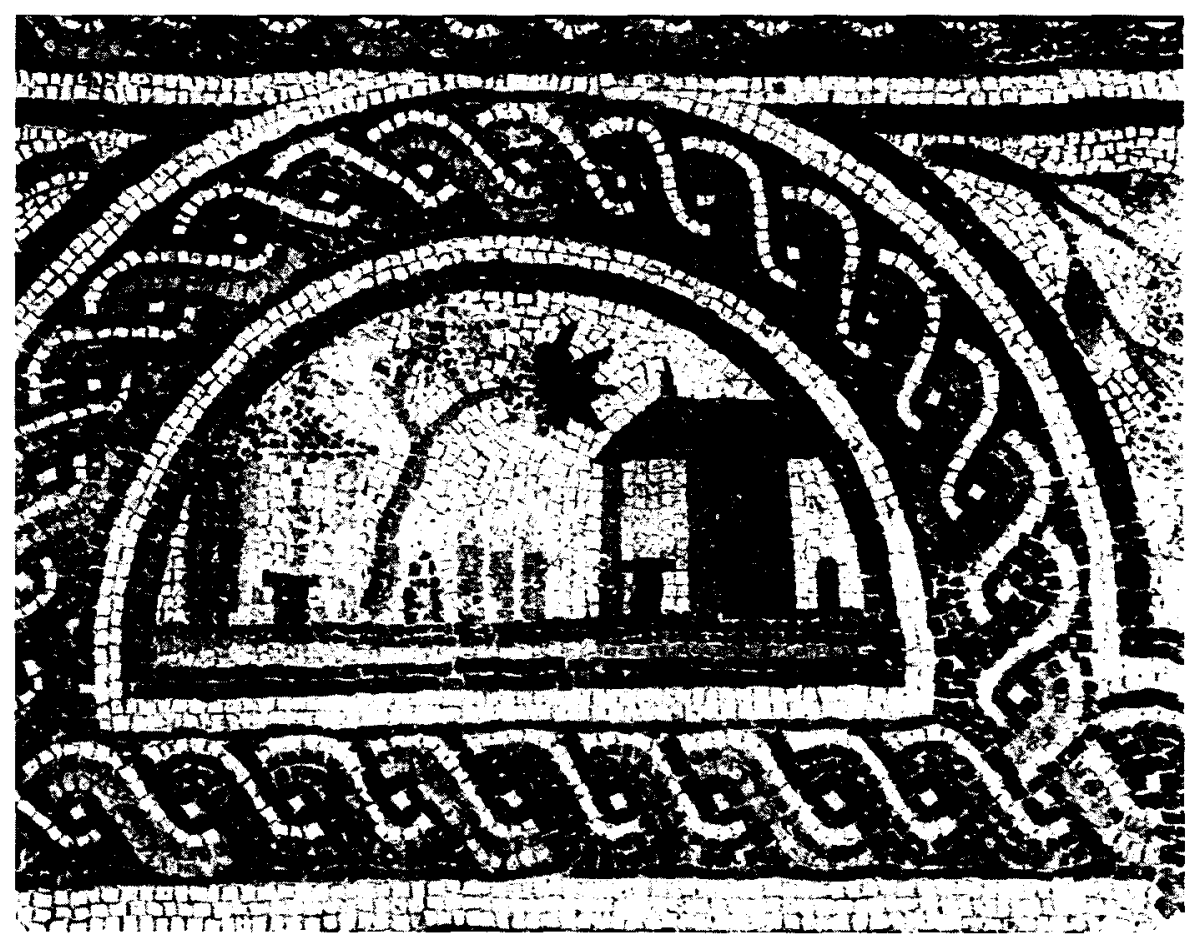

Figura 27. Mosaico de la Vega Baja, Toledo.

la derecha un pabellón y el de la izquierda una capilla o templete, albergando una estatua sobre un pedestal, posiblemente Príapo (figura 27).

En el pavimento perdido de Oued Atménia, fechado en el siglo IV, que procedía del caldarium de las termas de Pompeianus, nombre que aparecía en la inscripción indicando con toda probabilidad el nombre del propietario ${ }^{58}$. Mostraba también el jardín de la villa, con árboles (palmera, ciprés), un pabellón, una dama sentada junto a un árbol, probablemente la domina, y un esclavo que sostiene una sombrilla protegiéndola del sol (figura 28).

Entre las representaciones de jardines no faltan las que muestran personajes realizando distintos menesteres relacionados con las flores. En la parte alta del mosaico de Piazza Armerina, que decora el ambulatorio 43,

\section{lám. III.}




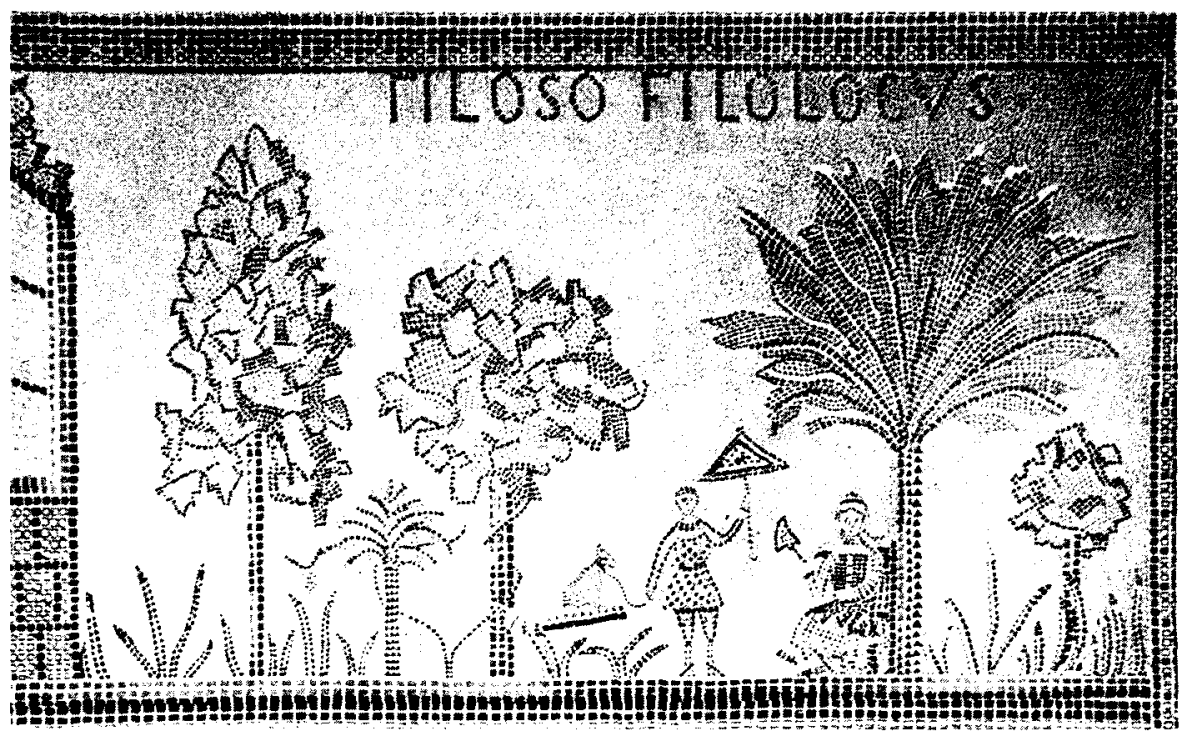

Figura 28. Mosaico de Oued Atménia.

posiblemente el cubiculum, aparece en niveles diferentes tres escenas conectadas entre si $^{59}$. En la superior se ve dos niños que tienen en las manos cestas de mimbre (canistrum) en las cuales meten flores que cogen de los árboles o arbustos situados en torno a ellos. En la escena central aparece a la izquierda una mujer sedente cogiendo flores de una cesta para hacer guirnaldas (psychai coronariae) que cuelgan de un árbol; a la derecha otra dama con cestos de flores en ambas manos, se dispone a dejar uno de ellos en el suelo. En la parte inferior un muchacho lleva sobre la espalda un palo en cuyas extremidades le cuelgan dos cestos de flores (saccus). Alrededor de las escenas se representan ramas y flores (figura 29).

Una escena semejante, dentro de un contexto de fiestas asociadas con la primavera y con los juegos de circo, se documenta en el mosaico del ábside del ambulatorio 45 de la misma villa siciliana, que también se ha identificado como posible cubiculum ${ }^{60}$. Aparecen, junto a un árbol y rodeadas de rosas, dos jóvenes sentadas en scabelli, tejiendo coronas de flores que están colgadas de las ramas del árbol, en donde figura una hoja de acanto, idéntica a la que aparece en el pavimento del peristilo 19d, que ha

A. Caranduni et alii, Filosofiana. La villa di Piazza Armerina. Palermo. 1982, 274-281, lám. 43b, figs. 172 y 173 .

Ibidem. 284-287, lám. 45b. 


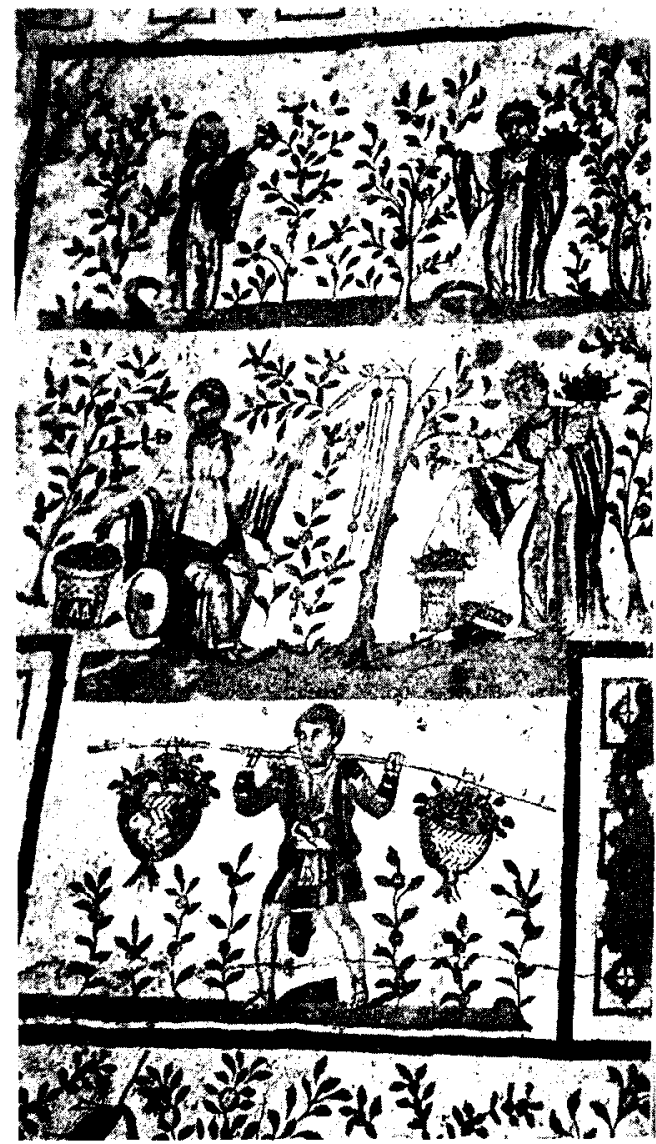

Figura 29. Mosaico de Piazza Armerina, hab. 43

sido interpretada como el símbolo de la dinastía Erculia o un elemento con significación apotropaico o de victoria lúdica. Abajo, sobre un arca, dos cestas que contienen dos palmas y una corona de flores, a los lados un saco de monedas (figura 30 ). Paralelos para esta escena de la industria de las flores aparecen en diversas pinturas de Pompeya como las de la Casa de los Vetii o de Macellum, con la confección de guirnaldas, y en cuatro pinturas de la bóveda de una cámara funeraria de la Iglesia de San Stefano Rotondo en Roma, con todo el proceso industrial: la recogida en cestos, transporte de los cestos y la verita de las guirnaldas ${ }^{61}$.

\footnotetext{
W. F. JASHLMSKI (1979), op. cit. (n. 1), 267-288, figs. 397-399 y 410.
} 


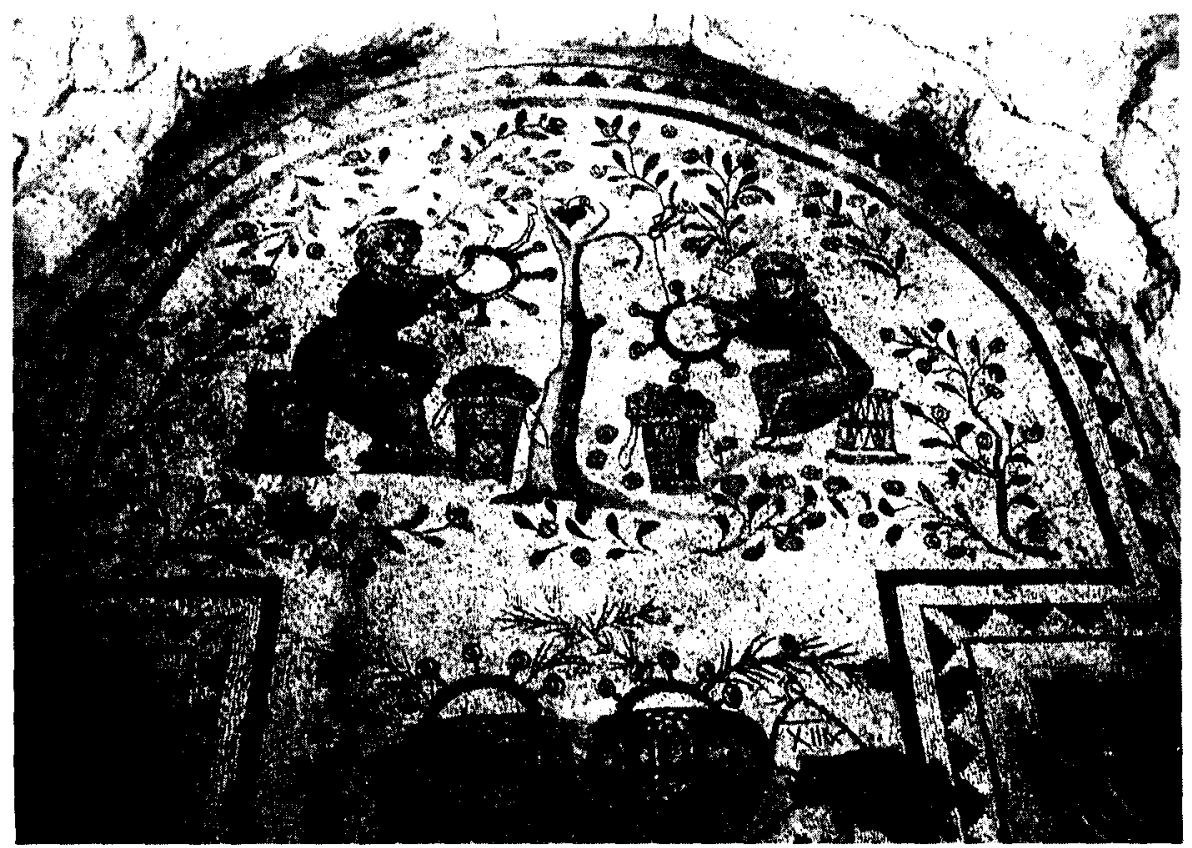

Figura 30. Mosaico de Piazza Armerina, hab. 45

Una escena del mismo género aparece en un cuadro conservado del mosaico del hipocaustum de la villa de Desenzano, que en origen eran cuatro y según los excavadores podrían representar las cuatro Estaciones ${ }^{62}$. En el asociado con la primavera figuran dos jóvenes con alas, sentadas en sellae, entrelazando guirnaldas de flores que cuelgan de un arbusto. Enmarcando la escena se representa guirnaldas con dos aves afrontadas (figura 31) 63 .

En contra de nuestra opinión igualmente se ha interpretado como Es taciones las cuatro figuras femeninas representadas en cuatro paneles, de principios del siglo v, procedentes de las termas de Sidi Ghrib, situados en los ángulos del frigidarium, que se conservan actualmente en el Museo

D. SCAGl IARINI Cofil AITA et alii. Villa romana Desenzano. Roma, 1992, 70-72, fig. 51

Guirnaldas de flores asociados a erotes aparecen en un mosaico de Thina, inv. Mos. Afr. II. n' 29: en la Casa de los Caballos de Cartago. J.W. SAl OMONSON. La mosaique aux chevaux de l'antiquarium de Carthage. La Haya. 1965. 38. lám. XXX, 1: y en El Jem, L. Foucht.12, op. cit. (n. 20), 141, fig. 18. Un erote con cesto de flores aparece en el mosaico de Panes Perdidos (Badajoz). J.M. Al varil 7 Mari ine/ y T. Nogales, "Los mosaicos de la villa de Panes Perdidos, Solana de los Barros (Badajoz), Anas 8. 1994-1995 (en prensa). 


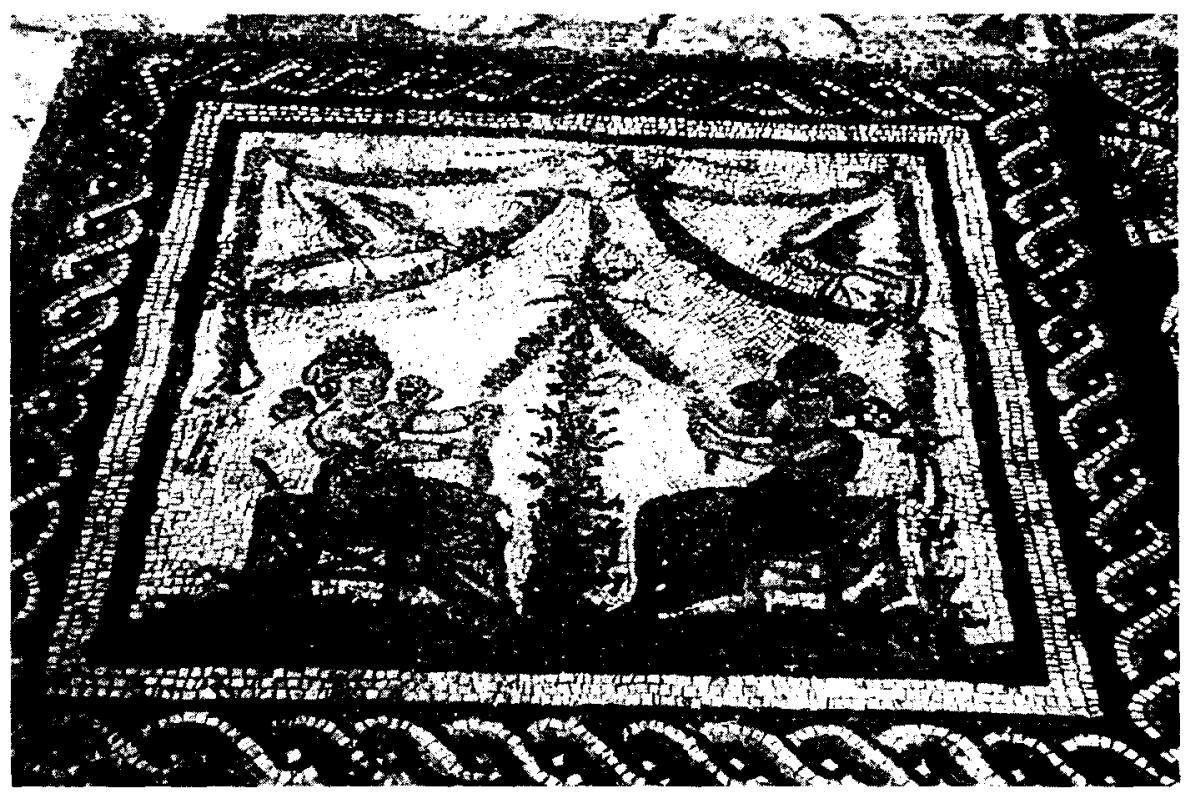

Figura 31. Mosaico de Desenzano.

de Cartago ${ }^{64}$. En cada uno de los paneles, que presentan gran similitud entre ellos, está representado un jardín de rosas rodeado de una cerca y delante de la cual destaca una mujer danzando. Alternativamente dos vertedoras de agua, vistas de espaldas, y dos vertedoras de rosas, vistas de frente, y sus pies un cesto con asas repleto también de rosas (figura 32).

Entre las representaciones norteafricanas de ambiente rural destaca un mosaico en el que se combina la presencia de los domini y las ofrendas de frutos y flores de sus servidores que tiene lugar en el jardín exterior, figurado mediante una balaustrada, plantas y árboles, que como indica $\mathrm{Pa}$ lladio se encuentra muy cerca de la villa (XXXIV), la cual está representada también en el pavimento. Es el conocido mosaico de dominus lulius de Cartago, fechado en el siglo iv o comienzos del $v$ y que se conserva en el Museo de El Bardo ${ }^{65}$. En el registro inferior se encuentra, a la derecha el dominus sedente recibiendo de un mensajero una carta enrollada en la que aparece una inscripción con su nombre; a la izquierda la domina en pie mirándose en un espejo y en torno a ella dos sirvientes, uno la ofrece

M. BI.AnChafi)-Lemef et alli. op. cit. (n. 51), 155 y 290, figs. 117 y 118

K.M.D. Dunbabin, op. cit. (n. 20), 119-121, 252, lám. 109. 


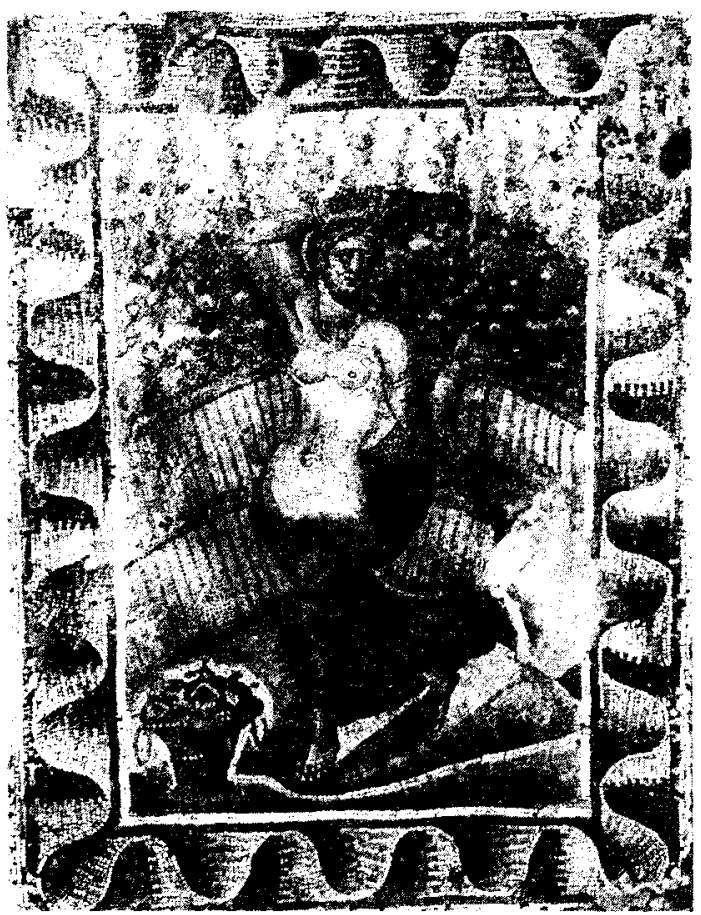

Figura 32. Mosaico de Sidi Ghrib.

un collar y una caja de joyas y el otro la presenta un canastillo de rosas, este último ha sido interpretado por su actitud como la representación de la primavera (figura 33). Igualmente está figurado el jardín interior de la villa por medio de un árbol que sobresale del edificio ${ }^{66}$. Todas las escenas del mosaico reflejan, además, las costumbres sociales de la nobleza agraria africana de la Antigüedad tardía ${ }^{67}$.

a. Se puede considerar también jardines interiores los árboles figurados en las villas del mosaico de Arróniz (Navarra), fechado a fines del siglo 11 o comienzos del IV, M.P. SAN Nicolas PFURAL, «Arquitectura rural en los Mosaicos Hispanos", XII Convegno di Studi su L'Africa romana (Olbia 1996). 1998, Sectores $V$ y VIII. En algunos mosaicos norteafricanos del Bajo Imperio se confunde el paisaje puro de la ciudad con sus propios jardines. Para estos pavimentos cf. G. LOPEZ Montf AGUUO, "Representaciones de ciudades en los mosaicos del Norte de Africa". L'Africa Romana X (Oristano 1992), 1994, 1.241-1.257.

Concretamente esta escena coincide con la referencia de Marcial de que el colono saluda a su maestro y de paso ofrece presentes a la mujer (III 58, 33-40, VII 31, 9), cf. P. VEYNE, "Les cadeaux des colons à leur propiétaire. La neuvième bucolique et le Mausolée d'igel", Revue Archéologique. 1981, 2, 245-252. Para la vida rural cf. Th. PRECHE ur-CANongt. La vie rurale en l'Afrique romaine d'après les mosaiques. Túnez, 1963, passin. 


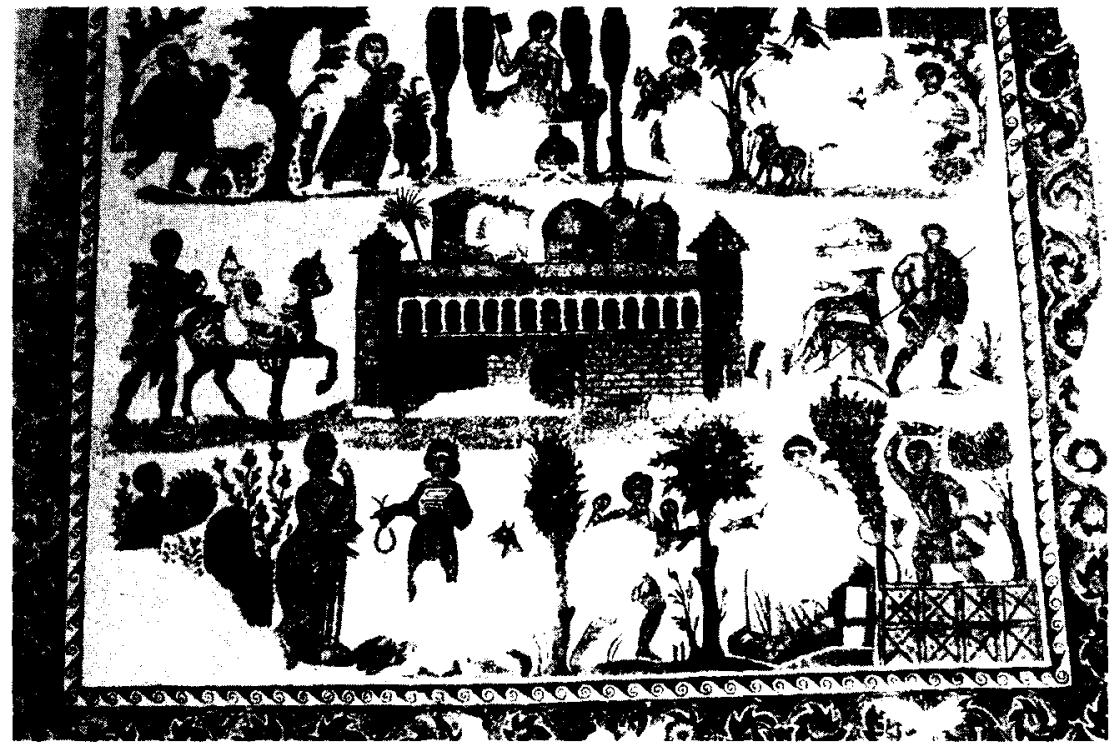

Figura 33. Mosaico de dominus lulius, Cartago.

En uno de los mosaicos de Tabarka (Túnez), de la misma fecha que el anterior y conservado igualmente en el Museo de El Bardo ${ }^{68}$, figura, rodeando la villa, el jardín exterior con árboles frutales, rosas y aves en un pequeño lago (figura 34 ).

El mosaico de Vitalis que pavimentaba el vestibulum situado en la fachada Este de la villa residencial de Els Ametllers en Tossa de Mar (Gerona), de finales del siglo iv o inicios del $v$, se representa en el emblemata cuatro columnas formadas por triple arcada con celosia, que surgieren el pórtico ${ }^{69}$. Las centrales son claramente de estilo dorso y albergan en su espacio central una figura femenina que ha sido interpretada como la alegoría del lugar de Turissa ${ }^{70}$; mientras que las columnas de los extremos

6y K.M.D. DunBaBin, op. cit. (n. 20), 122, lám. 112; T. SARNOWSKI, La représentation de villas sur les mosaíques africaines. Varsovia, 1978, 89, lám. 4; J.-N. RoBerT, op. cit. (n. 2), 74 ss.

69 I. RODÁ, "Iconografía y epigrafía en dos mosaicos hispanos: las villae de Tossa y Dueñas", VI Coloquio Internacional sobre Mosaico Antiguo (Palencia-Mérida, 1990), 1994, 35.40, fig. 1.

* La inscripción que presenta el mosaico se ha traducido "Si Vitalis tiene salud, Turissa es feliz. Producto del taller de Felix". cf. C. BALmell. y J.P. Darmon, "L'artisan-mosaïste dans l'Antiquite Tardive. Réflexions à partir des signatures", en Artistes, artisans et production artistique au Moyen Age (Rennes, 1983). París 1993, vol. I, 235-253; G. FaBHE et alii, Inscriptions Romaines de Catalogne, III. Paris, 1991, 11; J. Gomez PAL Aafes, Edición y comentario de las inscripciones sobre mosaicos de Hispania. Inscripciones no cristianas. Roma, 1997, 99-101, lám. 33 (con bibliogratía anterior). 


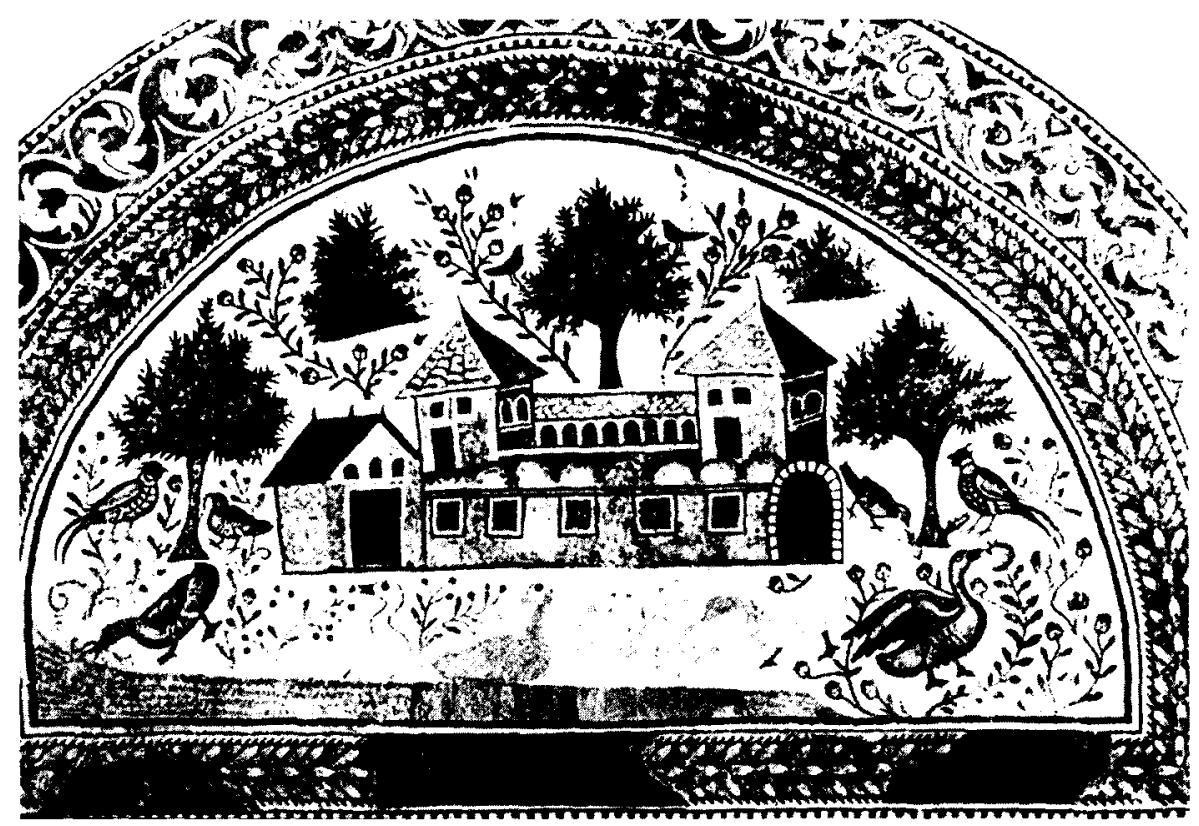

Figura 34. Mosaico de Tabarka.

son simples y bajo sus vanos existen elementos vegetales estilizados sugiriendo el jardín (figura 35 ). La representación solamente del pórtico a base de arcadas también con motivos florales y árboles frutales se encuentran en pavimentos de Grecia, Galia y Norte de África, fechados entre los siglos $\vee$ y $V_{1}{ }^{71}$, algunos de ellos asociados ya a un ambiente cristiano, como el mosaico norteafricano de Orléansville (actual AI-Asnam), de triple arcada con columnas de estilo dorso, que tiene representado en el vano central capullos de rosas y una corona de laurel con el epitafio del obispo Repatus, y en los laterales cráteras con palomas rodeadas de flores ${ }^{72}$.

En sintesis, puede decirse que los espacios ajardinados aparecen en la musivaria romana desde el siglo i hasta el final de la Antigüedad y corres-

H. LAVAGNE et alii (1976), op. cit. (n. 13), 232-234; C. BALMELLE, "Le répertoire végétal des mosaistes du Sud-Ouest de la Gaule et des sculptures des sarcophages dits d'Aquitaine". Antiquitainé tardive 1 (1993), Les sarcophages d'Aquitaine (Actas du Colloque de Geneve, octobre 1991). 106, fig. 13 (acuarela del mosaico de Nérac, Lot-et-Garonne, con árboles en las arcadas y pámpanos en las columnas).

L. LESC,HI, Eludes d'epigraphie, d'archéologie et d'histoire africaines. Paris, 1957, 405, fig. 1 ; N. Duval y P.-A. FFVRIER, "Le décor des monuments paléochrétiens d'Afrique", Actas del VIII Congreso Int. Ant. Cristiana (Barcelona, 1969), 1972. lám. VI, fig. 8 


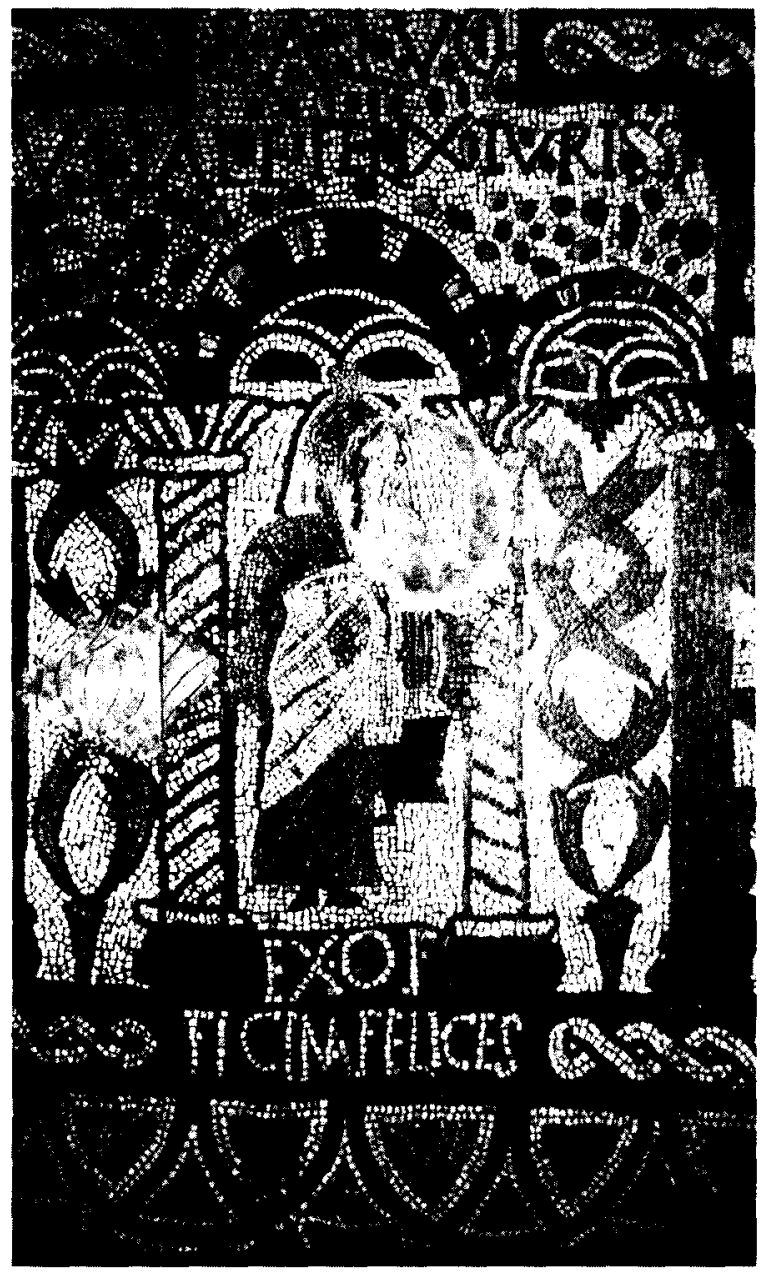

Figura 35. Mosaico de Els Ametllers. Gerona.

ponden a una representación simbólica de la naturaleza, heredada del mundo Oriental. Estas representaciones aparecen en todas las provincias romanas, en las domus y villae, perdurando en edificaciones cristianas. En la organización del espacio se utiliza la perspectiva lineal, tanto la cónica como la abatida, vista en alzado o en planta.

En cuanto al repertorio no constituye un conjunto unitario. En los mosaicos campanienses (parietales, columnas y suelo) se aprecia un efecto ilusionista idéntico a las manifestaciones pictóricas. En las restantes se 
distinguen por un aspecto más naturalista, que muestran, en algunas ocasiones, decoraciones claramente estilizadas.

En la composición del espacio ajardinado se distingue igualmente varias características. Unas por vegetaciones libres, en el mismo panel o en paneles contiguos, o encerradas en un espacio arquitectónico figurado (peristilo o pórtico). Otras reducidas a sencillas divisiones en arcadas con plantas o flores diversas. $Y$ una tercera caracterizada por complicados trazados, al hacer intervenir en ellos ejes principales y secundarios, normales - diagonales, divisiones geométricas, cuadrados, rectangulares, circulares o elípticas con un marcado preocupación de conjunto, cuyo mejor exponente es el mosaico de Loupian (Francia), el cual figura encerrado en un espacio de arcadas representando el peristilo-jardín.

También aparecen escenas con personajes realizando diversos menesteres relacinados con las flores, o la imagen del dios de la vegetación, Príapo; e incluso los propios domini en el jardín de su villa o la representación alegórica de la ciudad.

Son en definitiva, documentos bótanicos, hasta cierto punto "realistas" de la estética del jardín romano, espacio conocido a tráves de las fuentes literarias y restos arqueológicos. Al mismo tiempo tienen un valor simbólico en relación con la prosperidad y bienestar del propietario. 